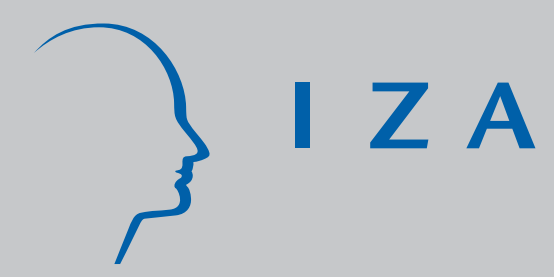

IZA DP No. 3704

Intrafamily Resource Allocations:

A Dynamic Model of Birth Weight

\author{
Emilia Del Bono \\ J ohn Ermisch \\ Marco Francesconi
}

September 2008 


\title{
Intrafamily Resource Allocations: A Dynamic Model of Birth Weight
}

\author{
Emilia Del Bono \\ University of Essex and IZA \\ John Ermisch \\ University of Essex and IZA
}

Marco Francesconi

University of Essex and IZA

\section{Discussion Paper No. 3704 \\ September 2008}

\author{
IZA \\ P.O. Box 7240 \\ 53072 Bonn \\ Germany \\ Phone: +49-228-3894-0 \\ Fax: +49-228-3894-180 \\ E-mail: iza@iza.org
}

\begin{abstract}
Any opinions expressed here are those of the author(s) and not those of IZA. Research published in this series may include views on policy, but the institute itself takes no institutional policy positions.

The Institute for the Study of Labor (IZA) in Bonn is a local and virtual international research center and a place of communication between science, politics and business. IZA is an independent nonprofit organization supported by Deutsche Post World Net. The center is associated with the University of Bonn and offers a stimulating research environment through its international network, workshops and conferences, data service, project support, research visits and doctoral program. IZA engages in (i) original and internationally competitive research in all fields of labor economics, (ii) development of policy concepts, and (iii) dissemination of research results and concepts to the interested public.
\end{abstract}

IZA Discussion Papers often represent preliminary work and are circulated to encourage discussion. Citation of such a paper should account for its provisional character. A revised version may be available directly from the author. 
IZA Discussion Paper No. 3704

September 2008

\section{ABSTRACT}

\section{Intrafamily Resource Allocations: A Dynamic Model of Birth Weight ${ }^{*}$}

This paper estimates a model of dynamic intrahousehold investment behavior which incorporates family fixed effects and child endowment heterogeneity. This framework is applied to large American and British survey data on birth outcomes, with focus on the effects of antenatal parental smoking and maternal labor supply net of other maternal behavior and child characteristics. We find that maternal smoking during pregnancy reduces birth weight and fetal growth, while paternal smoking has virtually no effect. Mothers' work interruptions of up to two months before birth have a positive effect on birth outcomes, especially among British children. Parental behavior appears to respond to permanent family-specific unobservables and to child idiosyncratic endowments in a way that suggests that parents have equal concerns, rather than efficiency motives, in allocating their prenatal inputs across children. Evidence of equal concerns emerges also from the analysis of breastfeeding decisions, although the effects in this case are weaker.

JEL Classification: $\quad$ C33, D13, I12, J13

Keywords: $\quad$ birth outcomes, smoking, mother's work, sibling estimators, instrumental variables, child health production functions

Corresponding author:

Marco Francesconi

Department of Economics

University of Essex

Colchester CO4 3SQ

United Kingdom

E-mail:mfranc@essex.ac.uk

\footnotetext{
*We are grateful to Jerome Adda, Sonia Bhalotra, Simon Burgess, Ken Chay, Andy Chesher, Lorraine Dearden, Bob Pollak, Carol Propper, Joao Santos Silva, Frank Windmeijer, and seminar participants at Bristol, City (London), Institute of Education (London), Institute for the Study of Labor (Bonn), LSE, Maynooth, Milan, NYU, Oxford, Verona, and ESPE 2008 (UCL) for helpful comments and suggestions. This research was supported in part by the UK Economic and Social Research Council Research Grant RES-000-22-2044.
} 


\section{Introduction}

There is growing evidence that differences in children's intellectual, emotional and personal development by parental education and socioeconomic status emerge at very early ages and that these differences are likely to cast a long shadow over subsequent achievements (Plomin 1999; Illsey 2002; Case et al. 2002; Feinstein 2003; Heckman 2000 and 2008).

To understand how such differences arise and develop, much of the recent social science research has focused on the effects of a variety of parental behaviors and, in particular, early (often preschool) investments on early child outcomes, such as cognitive and noncognitive development and psychological wellbeing. Examples of early parental post-birth behavior include childhood family structure (McLanahan and Sandefur 1994; Amato 2000; Hofferth 2006), maternal employment (Brooks-Gunn et al. 2002; Ruhm 2004; James-Burdumy 2005), child care choices (Blau 1999a; NICHD Early Child Care Research Network and Duncan 2003; Bernal and Keane 2008), parental income (Mayer 1997; Duncan and BrooksGunn 1997; Blau 1999b; Dahl and Lochner 2005), and parenting styles (Belsky and Fearon 2004; Aunola and Nurmi 2005). ${ }^{1}$ The idea that early investments are effective in alleviating inequality and raising life chances for the less advantaged has already generated many public policy programs around the globe, such as Head Start in the United States (Currie and Thomas 1995 and 2000) and Sure Start in Britain (Belsky et al. 2006). The belief that even earlier investments, such as preschool interventions aimed at improving cognitive and noncognitive skill formation, is also becoming increasingly influential (Heckman 2000 and 2008; Carneiro and Heckman 2003; Cunha and Heckman 2007).

By continuity, one can imagine that parental pre-birth decisions are also likely to be consequential, ranging from choices made long before the birth — such as educational achievement and occupational success of the parents - to other pregnancy-specific decisions - such as diet, smoking, alcohol consumption and choosing the baby's name (Fryer and Levitt 2004). Gaining insights into the way in which parents make their prenatal decisions is as essential to our understanding of how the family works and to policy as it is in the case of postnatal investments.

There is an economics literature on the effect of prenatal investments on child human capital. In recent years, however, this line of research has slowed down, with only a hand-

\footnotetext{
${ }^{1}$ A substantial body of research spanning several disciplines has also investigated the association of infant and early childhood parents' investments with later child outcomes (e.g., final educational attainment, teenage childbearing, labor market performance, family formation, and adult health). For comprehensive surveys, see Haveman and Wolfe (1995) and, more recently, Currie (2004), Cunha et al. (2006) and references therein.
} 
ful of studies published since the mid 1990s. In addition, and perhaps more importantly, less effort has been devoted to uncover the nature of parental preferences that drive such investments. However, knowing whether parents allocate resources to their children efficiently, so that they invest more in the better endowed children (Becker and Tomes 1976), rather than according to equity considerations, so that they compensate for low initial endowments by investing more in their worse endowed children (Behrman et al. 1982), has implications for the intergenerational transmission of human capital and the effectiveness of policies aimed at affecting initial endowments (Behrman 1997). For example, if the widening in the educational gap by parents' socioeconomic status is accompanied by parental investments that reinforce disparities in child endowments, then early intervention programs which disregard this feature of intrahousehold allocations are likely to be ineffective. That is, despite public policy, we may still observe large and persistent disparities in child outcomes because of the way in which parents respond to their children's human capital endowments.

These two areas of study - the emphasis on prenatal pregnancy-specific investments and intrahousehold allocation of resources - constitute the main focus of this paper. Our measures of child's human capital at birth are two widely used birth outcomes, birth weight and fetal growth. Biomedical, demographic and economic research has revealed that fetal growth is strongly related to the nutritional environment in utero and maternal cigarette smoking during pregnancy, and these, in turn, are associated with mother's health status and social class (Marmot 2005 and references therein; see also Currie and Hyson 1999). Nutrition in utero then affects brain growth and child's health (Barker 1995), and the existing evidence is that it continues to shape many realms of life — from infant mortality to later educational attainment and from earnings to health status - although there is some controversy on the exact size of such effects (e.g., Bartley et al. 1994; Behrman and Rosenzweig 2004; Case et al. 2005; Almond et al. 2005; Black et al. 2007).

Similar to biomedical and epidemiological research (e.g., Dougherty and Jones 1982; Kramer 1987; Lang et al. 1996), our aim is to estimate the technological determinants (production functions) of birth weight and fetal growth. This literature, however, usually fails to account for the fact that most of the determinants of birth outcomes are chosen by parents and thus reflect not only parents' productivities but also preferences. ${ }^{2}$ Economists have used a variety of methods to account for the endogeneity of parental inputs in health

\footnotetext{
${ }^{2}$ Some recent studies in the medical sciences recognize this endogeneity issue and use laboratory procedures to examine the effect of parental behavior on birth outcomes, such as examinations of human tissues, controlled trials of smoking cessations, and animal experiments. See Walsh (1994) and Slotkin (1998).
} 
production functions, from instrumental variables to sister and mother fixed effects. In this study, we use a 'method of moments' estimator, which nests the mother fixed effects estimator and an instrumental variables estimator that uses prenatal inputs during earlier pregnancies as instruments for differences in inputs between pregnancies. Similar estimation procedures have been used by Rosenzweig (1986), Rosenzweig and Wolpin (1988 and 1995) and Currie and Cole (1991 and 1993). In our analysis, as well as in those studies, identification relies on the key assumption that prenatal inputs associated with a specific pregnancy are uncorrelated with the idiosyncratic child endowment associated with that pregnancy. This allows us to estimate not only the direct effect of inputs on birth weigh/fetal growth, but also the parameters that govern the way in which parents respond to child endowments sequentially from one pregnancy to the next. In doing so, we use economic theory to interpret such dynamic responses as a result of efficient/equitable intrahousehold resource allocation decisions.

Our empirical analysis uses three different data sets, two from the United Kingdom the British Household Panel Survey and the Millennium Cohort Study - and one from the United States - the National Survey of Family Growth. We find that maternal smoking during pregnancy reduces both birth weight and fetal growth, while taking maternity leave or stopping work up to two months before birth improves both outcomes, especially in Britain. Paternal smoking has virtually no effect. But, when father's smoking is used as an instrument for mother's smoking rather than as a direct input, the effects of both mother's smoking and stopping work become larger in absolute value and precisely estimated. The results also indicate that parental behavior responds to child-specific unobserved health endowments and is correlated with persistent factors that are unrecorded in the data and vary across families. Therefore, estimation of child health production functions through either mother fixed effects models or instrumental variables techniques applied to crosssectional data are likely to yield biased results. Regardless of birth outcome and sample, there is consistent evidence of parents' choice over prenatal inputs across siblings that is driven by equity considerations. This emerges also in the case of postnatal investments, although the effects of unanticipated health shocks on breastfeeding decisions are generally small.

The next section discusses the related literature and the background against which our contribution can be assessed. Section 3 defines our analytical framework that hinges on birth weight production functions and describes our estimation strategy. Section 4 presents an optimizing model of parental investment decisions in children's human capital, which 
gives us an interpretation of parents' dynamic responses to the heterogenous idiosyncratic endowments of their children. Section 5 describes the three data sources and samples, while Section 6 reports our main empirical results. We first present the estimates of the effects of the endogenous inputs on birth outcomes and then turn to the estimates of the parameters capturing intrafamily responses. We next examine the effect of father's smoking, analyze the extent of heterogenous input effects along some observable characteristics (such as mother's education and age at birth), and look at the extent of sample selectivity bias. Section 7 discusses the key identification issues for (and presents results on) postnatal investment decisions, which are focused on breastfeeding behavior. Section 8 concludes and discusses some new directions for further research in this area.

\section{Background}

\section{A. Related Literature}

A well established empirical literature in economics has analyzed the effect of prenatal investments on birth outcomes. ${ }^{3}$ The distinction between prenatal investments and postnatal investments is important: for the former, parents have, if any, only a limited knowledge of that child's endowment. Examples of pregnancy-specific prenatal investments are maternal age at birth, parental smoking, and antenatal care. Postnatal investments include breastfeeding, playing, reading, visiting museums, and choosing specific types of daycare arrangements and schools. Note that the prenatal investments made during all the pregnancies subsequent to the first birth have a postnatal component for the children who are already born. For example, smoking during the second pregnancy is a prenatal investment that is likely to affect the birth weight of the second child, but is also a postnatal decision affecting the first child's human capital, if only indirectly through the budget constraint.

Only a handful of studies have allowed for such dynamic (or feedback) effects and these shall be the focus of our brief overview. In contrast, all postnatal investments are inherently dynamic, that is, parents are likely to respond to the idiosyncratic endowment of all existing children and, in turn, this response is likely to affect subsequent births. Moreover, with the exception of breastfeeding, the postnatal investments that are observed in large-scale surveys cannot be easily assigned to one child: for instance, a parent can read to one child while playing with another or take all children to the museum. We shall return to these

\footnotetext{
${ }^{3}$ Reviewing the vast biomedical and epidemiological literature on this topic is beyond the scope of this study. For reviews, see Walsh (1994) and Valero de Bernabé et al. (2004).
} 
issues in Section 7.

Our analysis is closely related to the work of Rosenzweig and Wolpin (1995). This is one of the very few studies on the technological determinants of birth outcomes that analyzes a dynamic intrafamily investment model with endowment heterogeneity. Their main focus is on the effects of mother's age at birth net of other maternal behavior and characteristics, including smoking, antenatal care, and birth spacing. Using data from the 1979 National Longitudinal Survey of Youth (NLSY) and prenatal inputs during previous pregnancies as instruments for the differenced inputs, they find that teen mothers have lower-gestation births, but have fetal growth rates that are greater than those of nonteen mothers. Due to large standard errors, the estimates of their dynamic model are not statistically different from those obtained through cross-sectional and mother fixed effects models. But their results offer strong evidence on the presence of intrafamily endowment responses, suggesting that intrafamily allocation decisions are driven by equity considerations, as mothers of a high-endowment first or second child are more likely to have the following child earlier and, as a consequence, these will tend to be low-gestation and high-fetal-growth births. The empirical focus, however, does not make this interpretation straightforward in their context. Likewise, the fact that they provide no analysis of postnatal investments does not allow us to see whether equity concerns are also reflected in parental decisions taken after the birth of each child.

Evidence of an equitable allocation of prenatal inputs across siblings has instead been explicitly found by Rosenzweig (1986), who looks at the relationship between birth spacing and gestation for a sample of US women and their children from the 1970 and 1975 National Fertility Surveys, and by Rosenzweig and Wolpin (1988), who consider the effect of birth spacing on birth weight and weight at 6 months for a sample of families in Columbia. Besides prenatal inputs, both these studies use family background variables as instruments for the differenced inputs. But this is not necessary, and in fact many parental and family background characteristics may be problematic as instrumental variables, because they can be either endogenous or weakly correlated with sibling input differences. These arguments can be extended to the many economic studies that employ family background variables as instruments for endogenous inputs in child health production functions (e.g., Rosenzweig and Schultz 1983a; Grossman and Joyce 1990; Currie and Cole 1993; see also below).

While the works by Rosenzweig (1986) and Rosenzweig and Wolpin (1988 and 1995) are concerned, at different degrees, with intrahousehold allocation decisions and estimate models that account for within-family and across-family variation in endowments, most of 
the existing studies of birth outcomes have analyzed the effect of specific determinants in the context of birth technology. One of the most commonly analyzed inputs in birth weight production functions is maternal smoking, which is often considered the single most important, modifiable factor affecting birth outcomes (Kramer 1987). Biomedical research has documented that smoking reduces birth weight by about 150 to 200 grams, that the longer the mother smokes during pregnancy the greater the effect on the baby's birth weight, and that smoking effects are weaker on gestation than on actual birth weight (Kramer 1987; Valero de Bernabé et al. 2004). But, as mentioned earlier, most of these studies are cross-sectional, ignoring family-specific unobservables and relying on the assumption that all children have the same idiosyncratic endowments or that child endowments do not affect parental behavior. Economists instead have been explicitly concerned with the issue of obtaining consistent estimates of child health production functions when all inputs (and not only mother's smoking) are correlated with unobservables.

One classical method to deal with input endogeneity problems is to employ instrumental variables. In the case of the effect of maternal smoking on child outcomes, identification is achieved through changes in the price of cigarettes or tobacco taxes across states and over time, parental characteristics (e.g., mother's education), family background variables (e.g., grandmother's schooling), or area characteristics (e.g., local government health expenditures and number of local hospitals with family planning services). This approach therefore relies on the assumption that cigarette price changes are independent of health endowments of parents and children, or that parental schooling is orthogonal to the unobserved factors associated with child health or, more generally, that there is no intergenerational transmission of endowments. The results from studies that use instrumental variables techniques are generally larger in absolute value than those found with cross-sectional regressions (Rosenzweig and Schultz 1983a; Grossman and Joyce 1990; Evans and Ringel 1999; Lien and Evans 2005).

Another strategy to control for the correlation between unobservables and parental inputs in child health production functions is to employ fixed-effects sibling models, which can be estimated only on mothers with multiple births (Rosenzweig and Wolpin 1991; Currie and Cole 1993; Abrevaya 2006). This approach recognizes that constraints and background characteristics cannot be used as instrumental variables and allows parental behavior to respond to family-specific endowments which can be transmitted across generations. But, to achieve identification, it must be assumed that idiosyncratic endowments of children in the same household do not affect parents' behavior, that is, there are no in- 
trafamily responses. Studies that use this approach report smoking effects that are usually lower in absolute value than the corresponding cross-sectional estimates (Abrevaya 2006; Tominey 2007).

Besides smoking, another potentially relevant input is mother's time off work during pregnancy. There has been a huge research about the effect of maternal employment as a postnatal investment on later child outcomes (e.g., Brooks-Gunn et al. 2002; Ruhm 2004; James-Burdumy 2005) but virtually none that has focused on it as a prenatal decision. ${ }^{4}$ While some cross-sectional biomedical studies have observed adverse associations of long hours of work, shift work, lifting loads, and high psychological stress on birth outcomes, others have found little effect (Croteau at al. 2006; Bonzini et al. 2007). In addition, comparing the labor supply responses of women from the United States and Britain, as we do here, might pick up different responses and offer important insights on future policy design because the two countries have different maternity leave policies (Waldfogel 1998).

Other determinants of birth outcomes that are included in our child health production functions are maternal age, parity, and sex of the child. Older women are usually observed to be at greater risk of preterm delivery, of giving birth to a child who subsequently dies, and of bearing a child with abnormal conditions (Royer 2005). The evidence on teenage childbearing instead is mixed, with some studies finding no association (Geronimus and Korenman 1993; Strobino et al. 1995) and others reporting more positive effects (Rosenzweig and Wolpin 1995). Both parity and child sex are inputs of the birth technology that relate to placental and fetal determinants of growth in utero rather than factors associated to maternal behavior. Most of the existing evidence on their effects comes from the epidemiological literature, which documents better birth outcomes for boys and for second and higher-order births (Butler and Alberman 1969; Love and Kinch 1965). Several studies use other prenatal inputs, such as antenatal care in the first trimester of pregnancy, alcohol consumption during pregnancy, and mother's weight before pregnancy; in this paper, however, we can analyze these inputs only in cross-sectional regressions. ${ }^{5}$

As mentioned in the Introduction, there is a huge social science literature analyzing

\footnotetext{
${ }^{4}$ Rosenzweig and Schultz (1983a) found that the number of months worked by a woman during pregnancy had no significant effect on birth outcomes, and thus excluded this variable from their published specifications.

${ }^{5}$ Recent research based on instrumental variables or fixed-effects sibling models has found small and insignificant effects of antenatal care (Abrevaya and Dahl 2005; Evans and Lien 2005) and of alcohol consumption (Abrevaya and Dahl 2005). Maternal weight before pregnancy, instead, has a strong positive effect on birth weight, even after accounting for intrafamily health heterogeneity and parental responses to child-specific health shocks (Rosenzweig and Wolpin 1995). An emerging strand of research looks at the effect of illicit drug use and, from cross-sectional analyses, finds evidence of an adverse association with birth outcomes (e.g., Reichman et al. 2006).
} 
the impact of postnatal investments on early and later child outcomes. Our estimation procedure allows us to estimate one aspect of postnatal investment behavior through the feedback effect that links endowment shocks to all subsequent births. Besides this, we also examine a more obvious postnatal investment, that is, breastfeeding. There is a wellestablished association between breastfeeding and a range of favorable health outcomes (Ip et al. 2007), and some evidence that breastfeeding might also improve cognitive development (Anderson et al. 1999). But these results are based on cross-sectional estimations and, indeed, when intrafamily health heterogeneity is taken into account, the breastfeeding benefits become smaller and statistically tenuous (Kramer et al. 2001; Der et al. 2006; Baker and Milligan 2008). Our interest in breastfeeding decisions, however, is motivated by the fact that they can provide us with novel evidence on intrahousehold resource allocation, which adds to the evidence drawn from the effects of prenatal inputs into the birth technology.

\section{B. Our contribution}

This paper makes four substantial contributions. The first is a contribution to the econometric literature that estimates models of intrahousehold resource allocation decisions with family- and child-specific heterogeneity and dynamic responses to endowments. Besides Rosenzweig and Wolpin (1995), no other study has pursued this line of analysis and nothing is known about Britain. We analyze three different data sources, which have never been used before to study birth outcomes and have complementary advantages and disadvantages with respect to the NLSY data used by Rosenzweig and Wolpin. Also, for the first time, we look at the impact of when the mother stops work (whether or not on maternity leave) during pregnancy, which in part reflects differences in labor market institutions between the United States and Britain and, as discussed earlier, raises several policy concerns. Unraveling this effect is therefore of clear general interest.

Second, in addition to the estimation of the effects of prenatal endogenous inputs on birth outcomes, we formulate an economic model of parental investment in children's human capital which allows us to interpret parents' dynamic responses to child endowments in terms of equity vis-à-vis efficiency concerns. The model has ramifications not only for the intrahousehold resource allocation literature but also for its policy implications. For instance, knowing if and how families adjust resources between children and respond to shocks over time has relevance for the design and provision of effective child-related transfers and services (Behrman 1997). 
Third, unlike most of the existing studies reported earlier, we also consider father's behavior (essentially father's smoking, because little variation is observed within and between families along father's labor supply). Only a handful of epidemiological studies have analyzed the relationship between father's smoking and child birth weight and established weaker associations than those between mother's smoking and offspring (e.g., Hennessy and Alberman 1998). These studies, however, typically fail to account for the fact that siblings both share similar bio-social environments and have specific idiosyncratic endowments to which parents may respond differently. By estimating the father-child link carefully, we can assess the extent to which indirect nicotine exposure adds to the maternal impact determined in utero (Gergen et al. 2001). We also consider the possibility that mother's smoking is measured with error so that, in a world in which partners match assortatively, father's smoking can be used as an additional instrument for maternal smoking (Kurzban and Weeden 2005). This is likely to improve our inference on the causal impact of mother's smoking over what the structural restrictions on the infant health production functions allow us to identify.

Fourth, we look at postnatal investments. We show that analyzing such investments in the context of child health production functions with intrafamily heterogeneity and dynamic responses to child endowments cannot be done without introducing strong untestable identifying restrictions. Therefore, rather than estimating the effect of postnatal investments on later child outcomes (which is the focus of most of the existing research across several disciplines), we build on the work by Rosenzweig and Wolpin (1988) and study the effects of endowment heterogeneity across households and sequential responses to idiosyncratic birth outcome shocks on postnatal investments. Although the reduced-form nature of this analysis should warrant caution, these estimates provide us with new evidence on parents' intrahousehold resource allocation decisions.

\section{Conceptual Framework}

\section{A. Infant Health Production Functions}

Although most studies of intrahousehold resource allocation with heterogeneous child endowments have been formulated in a static environment (Becker and Tomes 1976; Behrman et al. 1982; Rosenzweig and Schultz 1983a), it is natural to view the allocation decisions of parents with respect to the human capital of their children as the result of a dynamic process under uncertainty. 
In the context of birth outcomes, a straightforward example of within-family dynamics is given by the fact that, after the birth, say, of the first child, parents can observe his/her idiosyncratic endowment and take it into account while investing in the next child, even before this new child is born. Postnatal investments in the first child can also be affected by this new information. Building on such considerations, the next section will develop a sequential model of intrafamily investments in which resource allocation is affected by parental preferences, resource constraints, the technology of human capital production and by parents' sequential learning of child endowments as children are born. In this section we focus on the key components of our empirical analysis, namely, the technological relationship linking human capital at birth to parental behavior, such as smoking, and family and child endowments.

As in Rosenzweig and Wolpin's (1995) dynamic setup and in most of the static models of intrahousehold investments, we assume that the human capital at birth (e.g., birth weight), $h$, of child $i$ in family $j$ is given by:

$$
h_{i j}=X_{i j}^{\prime} \gamma+\mu_{j}+\phi_{i j}
$$

where $X_{i j}$ is a vector of prenatal endogenous inputs (e.g., parental smoking during pregnancy and mother's age at birth) and other characteristics (e.g., child's sex), $\mu_{j}$ is the family's (or mother's) endowment which, in part, is transmitted intergenerationally, $\phi_{i j}$ is the idiosyncratic child endowment of health that is not subject to the control of parents and is uncorrelated with $\mu_{j}$, and $\gamma$ is a vector of parameters. Equation (1) is the technology that parents use to produce the human capital at birth of their children. This is the primary object of our analysis. Of course, parental preferences may affect the relationship between endogenous inputs and unobservable endowments, while parental knowledge of child endowments changes when a child is born. The way in which preferences, technology inputs and endowments are linked will be formalized in Section 4. Before that, however, it is useful to clarify the assumptions about the characteristics of the unobservables in (1) and their effects on behavior since these drive our estimation procedure and interpretation.

\section{B. Estimation and Identification Strategy}

The parameters of interest are given by the vector $\gamma$ on the multiple endogenous inputs in the production function (1). A simple way of illustrating our econometric approach is to consider a family (or mother) with two children which uses only one input during pregnancy, $x$ (say, smoking), to produce human capital at birth, $h$. Thus, we rewrite (1) 


$$
\begin{aligned}
& h_{1}=\gamma x_{1}+\mu+\phi_{1}, \\
& h_{2}=\gamma x_{2}+\mu+\phi_{2},
\end{aligned}
$$

where the subscripts refer to the $i$-th child $(i=1,2)$, and the $i j$ subscripts have been dropped for convenience.

In (2) and (3), prenatal parental behavior, $x$, has a direct effect on birth outcomes. Many studies of birth outcomes have also recognized that prenatal parental behavior is likely to be influenced by parents' unobserved endowments, $\mu$ (e.g., mother's health), and these in turn may affect birth outcomes of both their children. But if parents care about the outcomes of individual children, then parental knowledge of child-specific endowments, $\phi_{1}$ and $\phi_{2}$, may also influence resource allocation. That is, parents respond to child-specific endowments by changing their inputs during pregnancy. If each child's endowment is unknown prior to his or her birth, then $x_{1}$ is uncorrelated with both $\phi_{1}$ and $\phi_{2}$, while mother's smoking during the second pregnancy, $x_{2}$, is uncorrelated with $\phi_{2}$ but may be correlated with $\phi_{1}{ }^{6}$

If this is the case, under the orthogonality assumption that $\phi_{i}$ is correlated neither with $\mu$ nor with $x_{i}(i=1,2)$, we can write down the moment conditions that fully characterize this environment as follows:

$$
\begin{aligned}
\sigma_{h_{1}}^{2} & =\gamma^{2} \sigma_{x_{1}}^{2}+\gamma \sigma_{x_{1} \mu}+\sigma_{\mu}^{2}+\sigma_{\phi_{1}}^{2}, \\
\sigma_{h_{2}}^{2} & =\gamma^{2} \sigma_{x_{2}}^{2}+\gamma \sigma_{x_{2} \mu}+\sigma_{\mu}^{2}+\sigma_{\phi_{2}}^{2}, \\
\sigma_{h_{1} h_{2}} & =\gamma^{2} \sigma_{x_{1} x_{2}}+\gamma\left(\sigma_{x_{1} \mu}+\sigma_{x_{2} \mu}\right)+\gamma \sigma_{x_{2} \phi_{1}}+\sigma_{\mu}^{2}, \\
\sigma_{h_{1} x_{1}} & =\gamma \sigma_{x_{1}}^{2}+\sigma_{x_{1} \mu}, \\
\sigma_{h_{2} x_{1}} & =\gamma \sigma_{x_{1} x_{2}}+\sigma_{x_{1} \mu}, \\
\sigma_{h_{1} x_{2}} & =\gamma \sigma_{x_{1} x_{2}}+\sigma_{x_{2} \mu}+\sigma_{x_{2} \phi_{1}}, \\
\sigma_{h_{2} x_{2}} & =\gamma \sigma_{x_{2}}^{2}+\sigma_{x_{2} \mu},
\end{aligned}
$$

where $\sigma_{x_{1} x_{2}}$ is the covariance between $x_{1}$ and $x_{2}$, and the vector of unknown parameters is given by $\left\{\gamma, \sigma_{\mu}^{2}, \sigma_{\phi_{1}}^{2}, \sigma_{\phi_{2}}^{2}, \sigma_{x_{1} \mu}, \sigma_{x_{2} \mu}, \sigma_{x_{2} \phi_{1}}\right\}$.

\footnotetext{
${ }^{6}$ Although parents can rely on increasingly precise information on fetus development, the performance of screening methods able to detect fetal growth retardation or to predict preterm labor is still less than perfect (Mongelli and Gardosi 2000; Iams 2003). Moreover, there are no effective treatments to reverse or prevent these conditions (Goldenberg 2002; Alberry and Soothill 2007; Spong 2007), and, except in extreme cases, parents have only a limited scope to respond to such information during pregnancy.
} 
A natural estimation procedure for equations (2) and (3) with their implied population moments is to match sample (observed) and theoretical moments using generalized method of moments (GMM) techniques. Estimation of (1) by ordinary least squares (OLS), which is the procedure commonly used in the biomedical literature, will not produce consistent estimates of $\gamma$ if $x_{i}$ is correlated with $\mu$. This is easily seen by noting that the OLS estimator is obtained by dividing $\sigma_{h_{1} x_{1}}$ by $\sigma_{x_{1}}^{2}$ (or $\sigma_{h_{2} x_{2}}$ by $\sigma_{x_{2}}^{2}$ ). It is clear from the fourth and last moment conditions above that this estimator will only provide an estimate of $\gamma$ if $\sigma_{x_{1} \mu}=0$ and $\sigma_{x_{2} \mu}=0 .^{7}$

Mother fixed effects (FE) models take account of the common component $\mu$ shared by siblings, but impose that its correlation with parental behavior is the same for each sibling pair (that is, $\sigma_{x_{1} \mu}=\sigma_{x_{2} \mu}$ ). These models also do not allow for intrafamily sequential decision making, that is, they impose $\sigma_{x_{2} \phi_{1}}=0$. It is again easy to see that the $\mathrm{FE}$ estimator does not estimate $\gamma$ when $\sigma_{x_{2} \phi_{1}} \neq 0$ : in fact, the FE-sibling estimator is obtained by dividing $\sigma_{\left(h_{1}-h_{2}\right)\left(x_{1}-x_{2}\right)}$ by $\sigma_{\left(x_{1}-x_{2}\right)}^{2}$, which, using the expressions for these moments from the list of moments above, identifies $\gamma+\sigma_{x_{2} \phi_{1}} / \sigma_{\left(x_{1}-x_{2}\right)}^{2}$.

With unrestricted nonzero covariances, the seven unknown parameters in the seven moment equations shown above can be estimated by a method of moments, and the resulting estimator amounts to using a 'fixed effects instrumental variables' (FE-IV) procedure for estimating $\gamma$, as shown by Rosenzweig and Wolpin (1995). In this framework, any endogenous input associated with the pregnancy of the first child, say $x_{1}$, can be used as an instrument for the difference in inputs across sibling births, $x_{2}-x_{1}$. Similar instruments have been applied by Rosenzweig and Wolpin (1988) and Currie and Cole (1991).

The assumption that the prenatal inputs associated with a pregnancy are uncorrelated with the child-specific endowment of that pregnancy is sufficient to guarantee that the model specified above is just identified in the two-child family case. ${ }^{8}$ This is true even when the set of inputs in (2) and (3) is expanded, because the relationship between the number of observed moments and the number of parameters remains the same. ${ }^{9}$ In the case of three-child households and one input $x$, there are eight additional moment conditions

\footnotetext{
${ }^{7}$ If these correlations are nonzero, then parental characteristics (e.g., maternal schooling) and family background variables (such as grandparents' schooling) are unlikely to be valid instrumental variables, and so are local area characteristics (e.g., number of hospital beds per capita and the number of clinics with family planning in a given geographical area) as long as parents' choice of residential location is partly driven by family unobservables.

${ }^{8}$ As discussed earlier, knowledge in utero of $\phi$ implies that $\sigma_{x_{i} \phi_{i}}$ cannot be set to zero unless parents cannot act on that knowledge. If they can act on it, the system for two-child families is underidentified: there are at least two more parameters $\left(\sigma_{x_{1} \phi_{1}}\right.$ and $\left.\sigma_{x_{2} \phi_{2}}\right)$ than moment equations.

${ }^{9} \mathrm{It}$ is worthwhile emphasizing that identification comes about even without having direct measures of prices, family wealth or income that could affect parental decisions. See Rosenzweig and Wolpin (1994).
} 
(for $\sigma_{h_{3}}^{2}, \sigma_{h_{1} h_{3}}, \sigma_{h_{2} h_{3}}, \sigma_{h_{3} x_{1}}, \sigma_{h_{3} x_{2}}, \sigma_{h_{3} x_{3}}, \sigma_{h_{1} x_{3}}$, and $\sigma_{h_{2} x_{3}}$ ), and four additional parameters $\left(\sigma_{x_{3} \mu}, \sigma_{x_{3} \phi_{2}}, \sigma_{x_{3} \phi_{1}}, \sigma_{\phi_{3}}^{2}\right)$, and the system is overidentified. ${ }^{10}$ Again, the relationship between moments and parameters is not affected by the number of inputs included in estimation: that is, we have four additional degrees of freedom every time we include a new endogenous input.

In the method of moment estimation, we will partition our samples into two groups (that is, siblings from two-child households and the first three siblings from families with at least three children), and we will then optimize a weighted sum of group-specific objective functions, where the weights are given by the group sample sizes. This allows us to account for the fact that both the OLS and FE models are hierarchically nested in the FE-IV model as well as to provide straightforward evidence on the validity of the restrictions imposed on the data by our three different estimators.

From the moment equations listed above, the production function parameters $\gamma$ have a straightforward technology interpretation. But the parameters that capture the sequential nature of the intrafamily resource allocation problem $\left(\sigma_{x_{2} \phi_{1}}\right.$ in the example) do not, because they also involve parental preference and production function parameters. To interpret such parental response parameters, therefore, it is helpful to formulate a dynamic model of parental investment, which will be presented in the next section.

Before doing so, we ought to emphasize that the analysis of the effect of postnatal investments on child human capital requires a different setup. As mentioned in Section 2.A, when deciding on postnatal inputs, parents know the realization at birth of, say, the first child's endowment and can adjust to it and update their beliefs about the endowments of all future children. This changes the production function framework used so far in two important ways. First, the correlation between any given postnatal input, $x_{i}$, and the observed endowment of child $i, \phi_{i}$, cannot be set to zero (that is, $\sigma_{x_{i} \phi_{i}} \neq 0$ ). Second, the production functions for all children following the first must be appropriately modified, so that they also include inputs and endowments of all preceding siblings. Appendix B shows that, with this new framework, the effect of postnatal inputs cannot be identified, even under strong orthogonality restrictions (e.g., even when all inputs on preceding siblings are excluded). For this reason, we will not estimate postnatal production functions. Section 4 will reiterate the problem of estimating the effects of postnatal investments on human capital, while Section 7 will examine postnatal investments only with the aim of gaining

\footnotetext{
${ }^{10}$ Appendix A reports such additional moment equations in the case in which there is only one prenatal input.
} 
insights into the issue of intrahousehold resource allocations.

\section{A Dynamic Model of Parental Investment in Children's Human Capital}

In this model, each family is assumed to have two children. Parents can make investments in each child during a prenatal period (i.e., pregnancy) and a postnatal period. The pregnancy for the first child is in the first period (denoted a), and the pregnancy for the second is in the second period (denoted b), during which time the parents also make postnatal investments in the first child. In the third period (c), only postnatal investments for the second child are made. The model is, therefore, concerned with household decisions over three periods. Parents choose resource inputs to human capital investment in their two children $\left(h_{1}\right.$ and $\left.h_{2}\right)$ and consumption of a public good $(G)$. We also assume that there is no borrowing or lending across the periods. Parents' preferences in each period $t$ are given by: ${ }^{11}$

$$
U^{t}=U\left(G_{t}\right)+W\left(h_{1}, h_{2}\right),
$$

with $t=a, b, c$, and lifetime parental utility is given by $\sum_{t} U^{t}$. The constraints include two human capital production functions (one for each child):

$$
\begin{aligned}
& h_{1}=f\left(x_{1 a}+\phi_{1}, x_{1 b}\right) \\
& h_{2}=f\left(x_{2 b}+\phi_{2}, x_{2 c}\right),
\end{aligned}
$$

where $x_{i t}$ is the parents' input into human capital production for the $i$-th child in period $t$ and $\phi_{1}$ and $\phi_{2}$ are idiosyncratic birth endowments. There is also a parental resource constraint for each period $t$, which is given by: ${ }^{12}$

$$
y_{t}=G_{t}+x_{1 t}+x_{2 t}
$$

where $y_{t}$ is parents' resources, and $x_{2 a}=x_{1 c}=0$ because of the timing of children in the model. The dynamic nature of the problem comes through human capital investment. ${ }^{13}$ This time allocation problem is solved by maximizing $\sum_{t} U^{t}$ subject to (4)-(6) in

\footnotetext{
${ }^{11}$ The implications of this model do not change when parental preferences are allowed to depend also on the consumption of private goods which could enter the human capital production functions, such as smoking (see below).

${ }^{12}$ For simplicity, but without loss of generality, prices have been normalized to one.

${ }^{13}$ The specification of (6) implies a trade-off between resources allocated to prenatal investments in the second child $\left(x_{2 b}\right)$ and resources allocated to postnatal investments in the first child $\left(x_{1 b}\right)$. Although this trade-off cannot be easily assessed for some inputs (such as mother's age at birth or smoking), it does capture the notion that household resources are scarce and some must be allocated to one child rather than the other.
} 
a backward manner (i.e., from period $c$ back to period $a$ ).

As in the previous section, we assume that parents do not know birth endowments, $\phi_{1}$ and $\phi_{2}$, before the child is born. This means that $\phi_{1}$ and $\phi_{2}$ are not known until the postnatal period for each child, that is, periods $b$ and $c$ for child 1 and 2, respectively. Prenatal investment in the first child, $x_{1 a}$, is clearly independent of $\phi_{1}$ and $\phi_{2}$. We are primarily interested in how prenatal investment in the second child, $x_{2 b}$, depends on $\phi_{1}$ when it is revealed. The solution of the parents' problem implies the following first order conditions in period $b$ : $U_{G}=W_{1} f_{b}^{(1)}=W_{2} f_{b}^{(2)}$, where $U_{G}=\partial U / \partial G, W_{i}=\partial W / \partial h_{i}$, and $f_{b}^{(i)}=\partial h_{i} / \partial x_{i b}$ for $i=1,2$. In the second period, the resource allocation rules implied by the solution of the problem take the form $x_{2 b}=\psi\left(\phi_{1}, y_{b}\right)$ for the prenatal investments in the second child, and $x_{1 b}=\lambda\left(\phi_{1}, y_{b}\right)$ for the postnatal investments in the first child.

From the conditions for a maximum, the resource allocation rules have the following properties. First,

$$
\frac{\partial x_{2 b}}{\partial \phi_{1}} \equiv \psi_{1}=\frac{U_{G G} f_{a}^{(1)}\left(W_{11} f_{b}^{(1)}-W_{12} f_{b}^{(2)}\right)-W_{1} f_{b}^{(2)} W_{12} f_{a}^{(1)} f_{b b}^{(1)}}{D}
$$

where $D$ is the determinant of the matrix of second derivatives of the Lagrangian function, which is positive by the second order necessary conditions for a maximum, $f_{a}^{(1)}=\partial h_{1} / \partial x_{1 a}$, $f_{b b}^{(1)}=\partial^{2} h_{1} / \partial x_{1 b}^{2}, \partial U_{G G}=\partial^{2} U / \partial G^{2}$ and $W_{i j}=\partial^{2} W / \partial h_{i} \partial h_{j}(i, j=1,2)$. The second order necessary conditions also entail that $U_{G G}+W_{i i}\left(f_{b}^{(i)}\right)^{2}+W_{i} f_{b b}^{(i)}<0(i=1,2)$. It is clear from (7) that both preferences and production technology affect the parents' response to the birth endowment of the first child.

Second, the impact of the first child's idiosyncratic endowment on postnatal investment in that child is given by:

$$
\begin{gathered}
\frac{\partial x_{1 b}}{\partial \phi_{1}} \equiv \lambda_{1}= \\
\frac{-U_{G G} f_{a}^{(1)}\left(W_{11} f_{b}^{(1)}-W_{12} f_{b}^{(2)}\right)-W_{11} f_{a}^{(1)} f_{b}^{(1)}\left(W_{2} f_{b b}^{(2)}+W_{22}\left(f_{b}^{(2)}\right)^{2}\right)+f_{a}^{(1)} f_{b}^{(1)}\left(W_{12}\right)^{2}\left(f_{b}^{(2)}\right)^{2}}{D}
\end{gathered}
$$

where $f_{b b}^{(2)}=\partial^{2} h_{2} / \partial x_{2 b}^{2}$. Finally, the effect of parents' resources on prenatal investment in the second child is

$$
\frac{\partial x_{2 b}}{\partial y_{b}} \equiv \psi_{2}=\frac{U_{G G}\left[W_{11}\left(f_{b}^{(1)}\right)^{2}+W_{1} f_{b b}^{(1)}-W_{12} f_{b}^{(1)} f_{b}^{(2)}\right]}{D} .
$$

It is plausible that $W_{12}>0$. For instance, in the CES formulation of $W$ used by Behrman et al. (1982), this is the case. While not necessary conditions for a maximum, we assume strict concavity of the $U, W$ and $f$ functions, so that $U_{G G}<0, W_{i i}<0$ and 
$f_{b b}^{(i)}<0(i=1,2)$. It then follows from (7) that $\partial x_{2 b} / \partial \phi_{1}>0$. Thus, mothers who have unexpectedly better endowed (e.g., larger birth weight or higher $\phi_{1}$ ) first children tend to devote more prenatal resources to their second child (that is, they have higher $x_{2 b}$ ).

In equation (8), under these same concavity assumptions, the first two terms on the right hand side are negative, while the final term is positive when $W_{12}$ differs from 0 . In the case where $W=w\left(h_{1}\right)+w\left(h_{2}\right)$ (i.e., parents' preferences over their children's human capital are additively separable), $W_{12}=0$, and so $\partial x_{1 b} / \partial \phi_{1}<0$. That is, postnatal investment in the first child is smaller when his/her birth endowment is larger. Overall then, when $W_{12} \geq 0$, there is a tendency to shift resources from postnatal investments in the first child to prenatal investments in the second child when the first child's birth endowment is larger. As will become clearer below, these responses reflect intrafamily equity considerations.

The specification of the human capital production functions in (5) assumes that each production function is linear in the child's endowment. In a more general specification, with $h_{1}=f\left(x_{1 a}, x_{1 b}, \phi_{1}\right)$ and $h_{2}=f\left(x_{2 a}, x_{2 b}, \phi_{2}\right)$, it could be the case that $\partial^{2} h_{1} /\left(\partial x_{1 b} \partial \phi_{1}\right)=$ $f_{b \phi_{1}}^{(1)}>0$ as well as $\partial h_{1} / \partial \phi_{1}=f_{\phi_{1}}^{(1)}>0$; that is, a higher first birth endowment could increase the productivity of postnatal investments for the first child (as in Cunha and Heckman 2007). Equation (7) is then replaced by:

$$
\begin{aligned}
& \frac{\partial x_{2 b}}{\partial \phi_{1}} \equiv \psi_{1}= \\
& \frac{U_{G G} f_{\phi_{1}}^{(1)}\left(W_{11} f_{b}^{(1)}-W_{12} f_{b}^{(2)}\right)-W_{1} f_{b}^{(2)} W_{12} f_{\phi_{1}}^{(1)} f_{b b}^{(1)}+W_{1} f_{b \phi_{1}}^{(1)}\left(U_{G G}+W_{12} f_{b}^{(1)} f_{b}^{(2)}\right)}{D} .
\end{aligned}
$$

Equation (10) contains a negative term, $W_{1} f_{b \phi_{1}}^{(1)} U_{G G} / D$, which acts in the opposite direction of the other terms when $W_{12}>0$. This is because there is now an efficiency motive for more postnatal investment in the first child when his/her birth endowment is larger $\left(f_{b \phi_{1}}^{(1)}>0\right)$.

To see this more clearly, suppose parents' preferences over their children's human capital are utilitarian, $W=h_{1}+h_{2}$. Then, $\partial x_{2 b} / \partial \phi_{1}=W_{1} f_{b \phi_{1}}^{(1)} U_{G G} / D<0 .{ }^{14}$ In this case, there are only efficiency motives, and so a better birth endowment for the first child induces less prenatal investment in the second child and more postnatal investment in the first child. In general, therefore, both equity and efficiency considerations may be important for the parental response to the first child's endowment.

A linear approximation to the parents' resource allocation rule for prenatal investment

\footnotetext{
${ }^{14}$ In the case in which $f_{b \phi_{1}}^{(1)}=0$, when parents' preferences are utilitarian, then $\psi_{1}=\lambda_{1}=0$ and $\psi_{2}=U_{G G} W_{1} f_{b b}^{(1)} / D>0$.
} 
in the second child is

$$
x_{2 b}=\pi_{0}+\psi_{1} \phi_{1}+\psi_{2} y_{b}
$$

Depending on the specification of the technology, either equation (7) or equation (10) would provide the interpretation for $\psi_{1}$, which corresponds to $\sigma_{x_{2} \phi_{1}}$ of the previous section and embodies the key dynamic considerations parents use in their resource allocation decisions. In what follows, we shall estimate this parameter as well as the other dynamic parameters using the FE-IV approach outlined earlier. According to our model, therefore, if the sign of $\psi_{1}$ goes in the same direction as the sign of the effect of input $x(\gamma)$ in the production functions (5a) and (5b), i.e., it is positive in the case of positive inputs (such as maternal weight) or negative in the case of negative inputs (such as smoking), then equity considerations are likely to dominate the resource allocation decisions between children.

It is essential to point out again that the inclusion of mother's smoking requires a slightly more complicated model in which smoking is also a direct argument of the parents' utility function. Nevertheless, the interpretation based on equity-efficiency concerns is similar. In particular, if $\phi_{1}$ is smaller (larger), equity considerations will lead the mother to smoke more (less) during the pregnancy of the second child. This is because smoking is a source of utility to the mother, and she takes the opportunity to improve her own welfare when her first child has lower $\phi_{1}$ and sacrifices her own welfare when the first child has a larger $\phi_{1}$ to promote equity between the children.

A similar resource allocation rule for postnatal investment in the first child is given by:

$$
x_{1 b}=\varphi_{0}+\lambda_{1} \phi_{1}+\lambda_{2} y_{b}
$$

where $\lambda_{1}$ cannot be easily signed, even in the simplest case with linear-in-endowment production functions and positive $W_{12}$, as in (8). A sufficient (but not necessary) condition for $\lambda_{1}$ to be negative is that $W_{12}=0$.

To examine postnatal investment in the second child, we need to solve the parents' optimization problem in the last period. In period $c$, human capital investment in the first child is finished, and so $h_{1}$ is a state variable in the parents decision. Parents then choose $x_{2 c}$ to maximize $U^{c}=U\left(G^{c}\right)+W\left(h_{1}, h_{2}\right)$ subject to $h_{2}=f\left(x_{2 b}+\phi_{2}, x_{2 c}\right)$ and $y_{c}=G_{c}+x_{2 c}$, which implies $U_{G}=W_{2} f_{c}^{2}$. Standard comparative statics yield

$$
\frac{\partial x_{2 c}}{\partial \phi_{2}}=\frac{-W_{22} f_{b}^{2}}{D^{c}}
$$

where $D^{c}$ is negative by the second order condition. Thus, $\partial x_{2 c} / \partial \phi_{2}<0$; that is, postnatal investments in the second child are negatively affected by that child's idiosyncratic 
endowment. The same investments may also respond to the first child's human capital outcome. In particular, if $W_{12}>0$, then:

$$
\frac{\partial x_{2 c}}{\partial h_{1}}=-\frac{W_{12} f_{c}^{2}}{D^{c}}>0
$$

In Section 7, besides the estimation of relationships similar to (12), we shall examine reduced-form allocation rules for postnatal investments in the second and subsequent children which combine (13) and (14). With parental preferences driven by equity concerns, postnatal investments in the second child are expected to respond negatively to that child's idiosyncratic endowment, while first child's human capital (proxied by his or her birth weight and breastfeeding status) is expected to have a positive effect on postnatal investments in the second child.

\section{Data}

\section{A. Sources}

In order to estimate the econometric model described in Section 3, we need individual data on birth outcomes and pregnancy-specific parental inputs for multiple children in the same household. Because very few representative datasets contain this range of information, we use samples from three different sources, each with advantages and disadvantages.

The first data source is the British Household Panel Survey (BHPS). The BHPS is a continuing longitudinal study which has been carried out every year since 1991. ${ }^{15}$ Since 1999 the survey asked mothers to provide information on birth weight and gestation of all their children born since 1991. Thus, part of the birth outcome information (but not that on related inputs) is retrospective and may not cover all children in a given household. Over the first 15 waves covering the period 1991-2006, we can identify 1,339 singleton live births and 912 mothers with valid birth weight and gestation records as well as non-missing values for various measures of parental inputs.

As the size of the BHPS sample is relatively small and its representativeness might be an issue, we use data from the much larger Millennium Cohort Study (MCS). The MCS is a longitudinal survey of children born in the UK between 2000 and 2001, which are followed over time through a sequence of successive interviews. ${ }^{16}$ We have valid birth weight and gestation data and information on a wide range of parental inputs (including father's smoking) for 17,483 singleton births and mothers. Although the MCS is longitudinal (in

\footnotetext{
${ }^{15}$ Detailed documentation on the BHPS can be found at <http://www.iser.essex.ac.uk/ulsc/bhps/>.

${ }^{16}$ Information on the MCS is availabe at <http://www.cls.ioe.ac.uk/studies.asp? section=000100020001 $>$.
} 
the sense that it follows one birth cohort over time), it offers information only on one child per household, and thus cannot be used to estimate FE or FE-IV models to control for family-specific heterogeneity and the presence of dynamic effects.

The third source of data comes from the fifth cycle (1995) of the National Survey of Family Growth (NSFG). This collects data on a nationally representative sample of US women aged 15-44, who report their complete fertility and pregnancy histories. The NSFG data therefore are retrospective (for both outcomes and parental inputs) and contain little information on father's behavior, but are longitudinal and cover a large sample of mothers and children. ${ }^{17}$ We restrict our analysis to a sample of 12,166 singleton births dating from the early 1970 s to 1995 and 6,153 mothers.

\section{Measures}

Our two measures of birth outcomes are birth weight in kilograms and fetal growth (that is, birth weight in grams divided by gestation length in weeks). By examining them separately, we should be able to isolate factors that affect weight at birth by simply shortening gestation length from factors that act upon the rate of growth of the fetus at any given point in time. We also analyzed gestation and found results that are strongly consistent with those reported here. To save space, therefore, the estimates on gestation are not shown.

Figure 1 presents the distributions of the two birth outcomes by sample. Each measure has been regression adjusted, netting out year and quarter of birth effects, so that each has a mean of zero by construction. Although the three data sources are different in sampling, data collection and period coverage, the birth outcome distributions are remarkably close. Figure 2 plots the means of regression-adjusted birth weight by week of gestation. Again, the pictures are very similar across data sources. The NSFG data exhibit slightly greater birth weight at any given gestation length, especially between weeks 30 and 34, but the differences are never statistically significant at conventional levels. Table 1 confirms the similarity in birth outcomes across samples, irrespective of whether we look at the regression-adjusted measures or not, and also in terms of the proportion of children born at low birth weight (which is defined as a birth weight of less than 2500 grams). These summary statistics are close to those reported in most of the existing studies reviewed earlier (e.g., Currie and Cole 1993; Rosenzweig and Wolpin 1995; Almond et al. 2005;

\footnotetext{
${ }^{17}$ Complete information and documentation on the fifth cycle of the NSFG can be found at $<$ http://www.cdc.gov/nchs/about/major/nsfg/>.
} 
Abrevaya 2006; Black et al. 2007; Tominey 2007). ${ }^{18}$

We examine the effect of four inputs on birth weight and fetal growth. The inputs, which are likely to be correlated with the endowment variables as in (11), are mother's age at birth, whether the mother smoked during pregnancy, mother's employment patterns during pregnancy (whether she stopped working or took maternity leave less than one month before the birth, or between 1 and 2 months before the birth, or 3 or more months before the birth, or she did not work during pregnancy), ${ }^{19}$ and parity (whether the child is firstborn or not). In all regressions, we also control for the child's sex. Our primary focus is on maternal smoking and labor supply. A number of other commonly used inputs are not available in our two longitudinal data sources but only in the MCS, and are thus excluded from our main empirical analyses. These are the mother's weight just before pregnancy, whether the mother consumed alcoholic beverages during pregnancy, and whether she obtained prenatal care in the first trimester of the pregnancy. We have however performed various robustness checks with the MCS sample in which these other inputs have been included too. We shall return to this issue in Section 6.A. Father's smoking during pregnancy is another potentially important determinant of birth outcomes which will be analyzed in Section 6.D. Finally, we have re-estimated the FE-IV model on the NSFG data including also spacing between two births, that is, for births after the first, the interval in weeks between the last birth and the conception of the current birth, which can be identified separately from the difference in mother's age only if there are mothers with three or more births. But since this input was never statistically significant and did not alter any of our results, it has been dropped from the analyses reported below.

Despite the similarities in outcomes, our three data sources reveal clear differences in parental inputs. Table 1 shows that between 23 and 26 percent of British mothers smoked during pregnancy while only 13 percent of their US counterparts did so. The British figures compare well with existing statistics from other UK sources (e.g., Tominey [2007] which uses data from the 1958 National Child Development Study). The US figure, instead, is substantially lower than those reported in Currie and Cole (1993), Rosenzweig and Wolpin (1995) and Almond et al. (2005), although it is in line with the statistics presented in Abrevaya (2006). ${ }^{20}$ Father's smoking prevalence during pregnancy, which is available only

\footnotetext{
${ }^{18}$ Note that only 6-7 percent of all births in the three samples are low birth weight. The use of quantile regression methods might be useful (Abrevaya and Dahl 2005). But, with our data sources, uncovering nonlinear effects at the low end of the birth weight distribution (especially in the region of low birth weight) will come at the cost of very small sample sizes. In addition, applying our FE-IV estimator to quantile regression techniques is not straightforward and may be an interesting area for future research.

${ }^{19}$ Defining job interruption on the basis of gestation weeks leads to identical results.

${ }^{20}$ In the fifth cycle of the NSFG, pregnancy-specific smoking status of the mother is collected retrospec-
} 
for the two British samples, is roughly comparable to maternal smoking and involves 23 and 29 percent of births in the BHPS and the MCS, respectively.

Mother's employment patterns during pregnancy differ both between the BHPS and MCS samples, possibly reflecting secular differences given by the different time periods covered in the two surveys as well as differences in data collection, and between the British and US data, possibly reflecting time differences and country differences in labor market choices and maternity leave legislation. While 16 percent of the BHPS children had their mother working up to the month before birth, the corresponding figures are 30 and 24 percent for MCS and NSFG children, respectively. Conversely, about half of the children in the NSFG had a nonworking mother for the entire pregnancy as opposed to two-fifths in the BHPS and one-third in the MCS. The US data refer to births that occurred several years prior to the 1995 interview, and some might refer to a time when mothers had a slightly weaker labor market attachment or suffer from greater recall problems. In addition, for about one-fifth of the BHPS sample and one-eighth of the NSFG sample, we cannot precisely determine maternal employment status during pregnancy, and this may drive some of the cross-national discrepancies. In the sensitivity tests discussed in Section 6 , therefore, we will check whether excluding cases with missing maternal employment information leads to different results or not.

Although the three data sources display comparable child sex distributions, with roughly each sample being equally split between boys and girls, there are notable differences along the other inputs. On average, the BHPS mothers are almost three and a half years older at birth than their NSFG counterparts, perhaps reflecting the longer horizon over which the women in the US sample had to recollect and report their fertility histories. However, mean age at birth in the BHPS sample compares well with the corresponding figures reported in Tominey (2007), while the NSFG figure is in line with the statistics shown in Datar et al. (2006) for mothers in the 1979 National Longitudinal Survey of Youth. The MCS mothers are the oldest, but this may reflect the fact that the MCS information is collected only in relation to the cohort child rather than all children in a given household. The same differences in sampling procedures might help explain the differences in the proportion of firstborn across samples.

As mentioned earlier, we use a set of other potentially relevant inputs, which however

tively but only for births that occurred between 1991 and 1995. Our smoking status variable, therefore, is based on the detailed smoking history information which is available for all births. Because of this, we cannot rule out recall problems and measurement errors which could lead to a downward bias of our effect estimates. Our smoking estimates may then represent a lower bound of the true effects. 
can only be found in the MCS data. More than four-fifth of the MCS mothers obtained prenatal care in the first trimester of pregnancy, a figure that is greater than that reported in Rosenzweig and Wolpin (1995) but is close to those presented in Currie and Gruber (1996) and Abrevaya (2006). Less than 1 percent of mothers drank alcoholic beverages every day during pregnancy, while another 8 percent drank regularly every week, and over 70 percent consumed no alcohol during pregnancy. These figures are in line with those presented in Currie and Cole (1993), Rosenzweig and Wolpin (1995), and Datar et al. (2006). ${ }^{21}$ The mean maternal Body Mass Index (BMI) before pregnancy was close to 24 $($ s.d. $=4.4)$ corresponding to an average weight of about 63.8 kilograms, approximately 5 kilograms more than the average weight of the NLSY sample analyzed by Rosenzweig and Wolpin (1995).

Finally, in terms of postnatal investments, we shall focus on breastfeeding, using only the NSFG sample. ${ }^{22}$ Less than half of American children are breastfed and, conditional on initiation, they are breastfed for about 25 weeks. These figures compare well with the existing statistics presented in U.S. Department of Health and Human Services (2000), as well as with the data described in Datar et al. (2006) and in the exhaustive survey by Ip et al. (2007).

\section{Results}

\section{A. Baseline Estimates of the Effect of Prenatal Inputs on Birth Outcomes}

Table 2 presents the estimated effects of maternal smoking and labor supply during pregnancy on birth weight and fetal growth, using ordinary least squares and mother fixed effects models. Each model is estimated separately for the three different data sets. All specifications also include the other inputs discussed in the previous section, and the crosssectional models additionally control for mother's education and ethnicity.

The OLS estimates reveal that smoking during pregnancy reduces birth weight of British children by 190 and 200 grams according to the BHPS and MCS samples, respectively. These estimates correspond to about one-third of the relevant standard deviations

\footnotetext{
${ }^{21}$ In the next section, we will report results from specifications in which there is only one maternal drinking variable (mother drank every day). The other variables (mother drank regularly every week, every month, or less, or consumed no alcohol during pregnancy) were never statistically significant, and their inclusion never affected our main results.

${ }^{22}$ Breastfeeding information is also available in the MCS. This, however, is not used due to its crosssectional nature. As a robustness check, cross-sectional estimates obtained from the MCS data were similar to comparable cross-sectional estimates found with the NSFG sample. For space limitation, such results are not reported.
} 
and are largely comparable to those presented in the medical literature (Butler et al. 1972; Bouckaert 2000). Smoking reduces also fetal growth by 4.1 to 4.8 grams per week. Such effects line up well with the birth weight estimates, as they imply 170-190 gram birth weight reduction at the average gestation length. This indicates that smoking is negatively related to actual growth in utero, and does not simply affect gestation (Kramer 1987).

In the NSFG sample, the cross-sectional estimates of the effect of smoking give us a similar picture, although the estimated impacts are smaller than in the UK with a reduction in birth weight of 140 grams and a reduction in fetal growth of 3.6 grams per week (or one-fifth of the corresponding standard deviations). These smaller impacts may be partly driven by the larger measurement errors affecting the smoking variable in the NSFG. In any case, such estimates compare favorably with the existing US evidence, falling well within the 80-160 gram range reported in Rosenzweig and Wolpin (1995), the 100-150 gram range found by Abrevaya (2006), and the estimates shown in Currie and Cole (1993).

Controlling for the possible influence of mother-specific unobservable components with the within-mother fixed effects estimator does not affect the smoking estimates in either the BHPS or the NSFG, regardless of the outcome. This stability is in contrast with the evidence reported in Rosenzweig and Wolpin (1995) and Abrevaya (2006), who find larger estimates in absolute value from cross-sectional models than from FE-sibling models. Our NSFG sample is substantially smaller than the samples from the federal natality data estimated by Abrevaya, but it does not suffer from the potential drawbacks of the matching strategies used in that study to construct a data set containing mothers with multiple births. In relation to Rosenzweig and Wolpin, our sample is larger than their NLYS sample, while our OLS specifications include a greater set of covariates, in the attempt to net out the potential influence of confounding factors (such as race and education). In addition, the fact that the same qualitative results are found with the BHPS, which does not collect input information retrospectively and thus may have fewer measurement error problems, gives our results further statistical reliability.

Table 2 shows that children whose mothers always worked during pregnancy or took less than four weeks of leave before birth are born lighter and experience smaller fetal growth. In the BHPS sample, these results are large (up to two-fifth of a standard deviation) and robust to the inclusion of unobserved mother fixed effects. The US estimates differ, indicating that only work interruptions between one and two months before birth lead to a 60 gram gain in birth weight and to less than one gram gain in fetal growth (and this 
latter impact is significant only in the OLS model). ${ }^{23}$ The greater responsiveness of BHPS children's birth outcomes to their mothers' work interruptions may be suggestive of the statutory maternity leave conditions offered to pregnant women which, over our sample period, were likely to be more favorable to British mothers (Waldfogel 1998). Of course, the lower NSFG estimates might simply reflect measurement error that is likely to affect the US sample more due to its retrospective collection of input information.

All specifications also include mother's age and age squared, and dummy variables for child sex and firstborn. To save space, these estimates are not reported, but, for the sake of completeness, they are briefly discussed here. As found in earlier research, boys are between 115 and 150 grams heavier at birth than girls, and have a greater fetal growth of about 3-4 grams per week (Currie and Cole 1993; Abrevaya 2006). Such estimates are significant in all samples and for both birth outcomes. Being the firstborn child is typically associated with less favorable birth outcomes: firstborn children are estimated to weigh between 100 and 130 grams less than their higher-order siblings in both British samples, while the firstborn penalty is 40-70 grams and statistically insignificant in the NSFG. In the case of mother's age at birth, we find different results depending on estimation method and data source. In both MCS and BHPS samples, there is never evidence of an age effect. In the NSFG sample, instead, the OLS estimates indicate an age effect on both outcomes (especially on birth weight, with a $p$-value of the joint significance test of 0.013) and such that birth weight and fetal growth increase in mother's age at birth up to about age 28 and declines thereafter. These effects, however, are not robust to the inclusion of motherspecific fixed effects. Such results are in slight contrast with those reported by Rosenzweig and Wolpin (1995) but very much in line with those shown in Currie and Cole (1993) and Tominey (2007).

Finally, as mentioned in Section 5, we control for three other prenatal inputs (alcohol consumption, antenatal care, and mother's BMI before pregnancy) that can only be observed in the MCS, to check whether the effects of maternal smoking and labor supply vary or not. The OLS estimates are shown in Appendix Table A1. Drinking alcoholic beverages every day during pregnancy leads to worse birth outcomes (although these associations are

\footnotetext{
${ }^{23}$ As mentioned in Section 5, we checked whether excluding the cases with missing maternal employment information leads to different results or not. Unsurprisingly, the BHPS and NSFG sample sizes get smaller (943 and 9,255 observations in the two samples respectively), but the estimates on the labor supply variables remain unaltered, irrespective of outcome and sample. The only important change refers to smoking, whose effect becomes slightly weaker and insignificant in the case of the BHPS sample (with an estimate of -0.158 (s.e. $=0.111$ ) from the FE model), mainly as a result of greater standard errors (an increase that, in turns, may be driven by the reduced sample size). This pattern, however, is not observed in the NSFG sample.
} 
not always statistically significant at conventional levels), ${ }^{24}$ mothers with a greater BMI tend to have significantly heavier children, while antenatal care in the first trimester does not affect birth outcomes. F-tests of the hypothesis that the effects of such additional inputs are jointly zero are rejected, mainly because of the strong influence of BMI. But none of the results in Table 2 are sensitive to the inclusion of these three additional inputs. For instance, controlling for them jointly reduces the MCS smoking estimates in absolute value by 1 percent of a standard deviation for both birth weight and fetal growth. Therefore, even though the MCS cross-sectional estimates control neither for complex dynamic family behavior related to unobservables nor for possible influences of mother-specific fixed effects, they suggest that omitting such additional inputs is likely to generate only limited biases in the estimated responses of interest.

\section{B. Dynamic Responses}

Table 3 reports the estimates obtained from the FE-IV sibling model using the NSFG sample. The table contains the estimates of the production function parameters (1) (similar to those discussed earlier), the endowment covariance components implied by the unobserved mother-specific fixed effects shared among siblings, and the behavioral parameters which govern the allocation rule (11) and underpin parents' dynamic responses. For each outcome, we report two sets of estimates, one obtained from a fully unrestricted specification (column (i)) and another one in which all the statistically insignificant estimates of the endowment covariances from the unrestricted specification are set equal to zero in the attempt to improve estimation efficiency (column (ii)).

The table reveals that the production function parameter estimates of prenatal mother's smoking and labor supply are very similar to those of the FE model reported in Table 2. We always accept the hypothesis that the two models produce estimates of the effects of the direct inputs that are the same. Notice, however, that the FE-IV point estimates are greater in absolute value than the corresponding FE estimates, especially when they are statistically significant. This indicates that parents might sequentially respond to their children's endowments, even though such responses are not strong enough to alter the estimates of the production function parameters.

This conjecture is confirmed by the estimated correlations between either smoking or

\footnotetext{
${ }^{24}$ Other sensitivity checks, using either different drinking indicators or one dummy variable for mothers who did not consume alcohol during pregnancy, led to similar or even weaker results on drinking. Irrespective of the specification, the main inferences drawn from Table A1 do not change. Currie and Cole (1993) report insignificant negative associations of mother's drinking over the 12 months before birth and birth weight, and these range between 5 and 85 grams.
} 
labor supply variables and the birth weight and fetal growth endowment components, net of the effects of all the other prenatal inputs. Women with a high endowment are less likely to smoke and more likely to stop working one to two months before birth during their first three pregnancies (that is, smoking- $\mu$ covariances are negative and the work interruption- $\mu$ covariances are positive). In addition, among mothers with the same input$\mu$ correlations, those with a high- $\phi$ first or second child are less likely to smoke and more likely to take some maternity leave during subsequent pregnancies. These effects are always statistically significant; in specification (i), for example, the relevant chi-square statistics with 12 degrees of freedom are 27.8 and 29.1 for birth weight and fetal growth respectively. Such correlations, therefore, provide strong evidence on the presence of parents' dynamic responses to child idiosyncratic endowments. From the model developed in Section 4, they can be interpreted in terms of parents' equity concerns rather than in terms of efficiency arguments (Rosenzweig 1986 and Wolpin 1988).

A further (statistical) way of gauging the importance of dynamic responses is through the goodness of fit tests that are presented at the bottom of Table 3. Both the OLS and FE-sibling models are hierarchically nested in the fixed-effects sibling instrumental variables model, and thus chi-square tests on the validity of the restrictions imposed by the two nested alternatives can be computed straightforwardly. Irrespective of birth outcome, the results indicate rejection of the restrictions associated with both the OLS and FE estimators relative to the FE-IV estimator. Thus, models that allow for family fixed effects, child-specific endowment heterogeneity and intrahousehold sequential responses to child endowments tend to dominate standard FE-sibling and cross-sectional models.

Table 4 applies the FE-IV estimation procedure to the BHPS data. As the number of three-child families is much smaller in this sample, the table presents the smoking and labor supply estimates obtained on the two-child family subsample. ${ }^{25}$ We find results that echo those from the NSFG sample, albeit with larger standard errors for many estimates. In particular, the use of the FE-IV sibling estimator yields results on prenatal smoking and labor supply patterns that are similar to those of the FE estimator for both birth outcomes. This is true not only when the FE-IV estimates are compared to the FE estimates of Table 2, but also when they are compared to the FE estimates obtained on the BHPS

\footnotetext{
${ }^{25}$ The advantage of this selection is that we can estimate a smaller parameter set without loss of generality. As a check on robustness, however, we re-estimated the model on the whole sample, that is, including the 50 extra observations on three-child households. This estimation was performed with an extremely parsimonious model containing only one endogenous input at a time, and repeated separately for all inputs. The estimates are quantitatively very close to those reported in Table 4 , and are thus not shown for convenience.
} 
subsample consisting only of two-child families. Furthermore, the estimated endowment covariances suggest that parents' intrahousehold allocations are primarily driven by equity considerations. Parents, therefore, tend to shift resources to prenatal investments in the second child when the first child's birth endowment is larger.

A broadly similar picture emerges when we analyze the effect of prenatal inputs on the probability of a child being born at low birth weight (birth weight less than 2500 grams). Low birth weight has been found to be a powerful predictor of several adverse health and economic outcomes, and not just around birth but also later in life (Behrman and Rosenzweig 2004; Almond et al. 2005; Black et al. 2007). Exploring the existence of differential nonlinear effects at other points of the birth weight distribution is intriguing but beyond the scope of this paper and is left for future research.

The low birth weight results from the three samples and the three estimators are reported in Appendix Table A2. These are obtained from specifications that are identical to those used for birth weight and fetal growth. Smoking during pregnancy significantly increases the risk of low birth weight by 4 percentage points (a 70 percent increase) in the cross-sectional model of the MCS, by 6-11 percentage points in the BHPS (80-150 percent), and by 3-5 percentage points (45-65 percent) in the NSFG. But, contrary to the cases of birth weight and fetal growth, we find no evidence of an impact of mother's work interruptions during pregnancy, net of inputs and controls. Although the estimated effects are in the same direction as those found for the other two birth outcomes, they are never statistically significant and we cannot reject the hypothesis that they are jointly insignificant at conventional statistical levels. The estimates, instead, provide evidence on the validity of the restrictions imposed by the FE-IV model against the nested FE-sibling and crosssectional models. Again, we find support for dynamic intrafamily investments that are equitable rather than efficient, and these effects are statistically significant $\left(\chi^{2}(4)=16.6\right.$ in the BHPS sample, and $\chi^{2}(12)=28.7$ in the NSFG sample).

In sum, the more complex model of family behavior, which controls for the possible influence of mother-specific unobservables and permits maternal behavior to adjust to prior birth outcomes net of inputs, yields estimates of the production function parameters that are not very different from those of the FE-sibling and OLS estimators. While prenatal smoking is invariably found to worsen birth outcomes, the results on stopping work during pregnancy are mixed. There is evidence of a positive effect on birth weight and fetal growth of interrupting work between one and two months before pregnancy, although the magnitude of this effect is smaller than that estimated for smoking. Other labor supply 
patterns (from working during the whole pregnancy to staying out of the labor market altogether) are never significantly associated with birth outcomes. Finally, from the fixedeffects instrumental variables estimator on both the NSFG and BHPS samples, we find strong evidence in support of the notion that parents have equity concerns when making intrahousehold allocation decisions about their children's wellbeing.

\section{Heterogeneous Input Effects}

It is possible that the birth outcome responses to mother's prenatal smoking and labor supply vary by observable characteristics of the mother. To allow for this, we estimate OLS, FE, and FE-IV (fully unrestricted) models that distinguish mothers on the basis of education and age at first birth. ${ }^{26,27}$ The results from these regressions are in Table 5, which, for the sake of brevity, presents only the production function parameter estimates on fetal growth from the BHPS and NSFG samples and the chi-square tests of joint significance of the input- $\mu$ correlations and of the input- $\phi$ correlations that capture the sequential nature of parents' decision making.

The FE and FE-IV estimates reveal that the negative effect of maternal smoking is predominantly observed among children whose mothers gained low educational qualifications (panel A) or were relatively young at the birth of their first child (panel B). ${ }^{28}$ However, the relatively large standard errors around the estimates of highly educated and older mothers do not allow us to reject the hypothesis that the estimated parameters are equal. For example, the test that the FE-IV smoking estimate for low-education mothers in the BHPS sample is the same as the corresponding estimate for high-education mothers can be rejected with a $p$-value of 0.506 .

Stopping work during pregnancy tends to improve fetal growth more for low-education mothers than for highly educated mothers, especially among British women. ${ }^{29}$ This can

\footnotetext{
${ }^{26}$ In the BHPS sample, mothers with low education are those with O-level (or equivalent) qualifications or below, while mothers with high education are mothers with A-level qualifications or above. In the NSFG sample, low education are those with high school qualifications or below, while mothers with high education are mothers with some college qualifications or above. The age cut-off is set at 24 years. Both categorizations stratify the two samples into subgroups with relatively comparable numbers of observations

${ }^{27}$ Ethnicity is another interesting factor, but distinguishing our samples on the basis of mother's race leads to very small datasets, making it impossible to perform FE and FE-IV estimations on nonwhites. Distinguishing children by sex (that is, separating families with only boys from families with only girls and families with both boys and girls) is likely to offer insights on parental preferences for sons. We leave this analysis for future research.

${ }^{28}$ The age estimates are fairly robust to the choice of other age cut-offs. But estimations on younger (e.g., below age 19 at first birth) or older (e.g., above age 35) subsamples cannot be performed due to their small size.

${ }^{29}$ The only case in which we can reject equality of the parameter estimates is for the FE-IV estimates in the BHPS sample of stopping work between one and two months before pregnancy $(p$-value $=0.027)$.
} 
reflect an occupational gradient, whereby low-education women are more likely to be engaged in physically demanding jobs and, in line with the available biomedical evidence (Meyer et al. 2007), might obtain greater infant-health benefits from job interruptions before birth. We also find evidence that job interruptions are more beneficial to older women in the BHPS but not in the NSFG, in which we cannot detect any labor supply heterogeneity along the age divide. Again, fatigue and stress might be critical ingredients which can be more relevant to older women.

The estimated endowment correlations from the FE-IV models (not shown) are in line with the findings reported earlier. In particular, low-education women with a high endowment (positive input- $\mu$ correlations) are less likely to smoke and more likely to stop working. All such correlations are jointly significant, albeit only weakly in the case of younger women in the BHPS and older women in the NSFG. Moreover, among mothers with the same input- $\mu$, those with a high- $\phi$ first or second child are less likely to smoke and more likely to take some maternity leave during subsequent pregnancies. Input allocations across children in the same household, therefore, are likely to be driven by equity concerns. Such dynamic effects are strong across all groups, with the exception of children born to highly educated and older women in the BHPS sample.

\section{The Effect of Father's Smoking}

So far, we have only looked at maternal inputs. Fathers, however, can affect birth outcomes in a number of ways. Their biological influences (for instance, through fitness, age, healthiness, height, and weight) are obvious (e.g., Yang et al. 2007), but these are not the focus of our analysis, partly because they are not available in the data sources under analysis. Fathers can also affect birth outcomes through their behavior. For example, economically successful fathers may afford to buy higher-quality food for their partners who can therefore enjoy better diets while pregnant. But father's income is strongly correlated with mother's education (which we have already analyzed in Section 6.C), while the variation in father's labor supply within households is too limited to be identified with FE or FE-IV sibling models. In what follows, therefore, we focus on one specific prenatal paternal behavior, i.e. smoking, which has been seldom analyzed and for which we have inconclusive results (see the discussion in Section 2).

Father's smoking during pregnancy is believed to generate indirect nicotine exposure (Hennessy and Alberman 1998), which may add to the direct maternal impact documented 
earlier. ${ }^{30}$ Using the two British samples that contain father's smoking information, we performed two sets of new regressions. The results (not shown) from the first set of regressions, in which the father's smoking variable replaced mother's smoking, point to a negative effect of father's smoking on birth weight and fetal growth. This effect, however, is at most half of the magnitude in absolute value of the effect of mother's smoking reported in Tables 2 and 4, and is only significant in the MCS sample. The results from the second set of regressions, in which both father's smoking and mother's smoking variables are included, are reported in Appendix Table A3. While the effect of maternal smoking remains significant and as strong as it was before, that of paternal smoking becomes smaller and never significant in the BHPS sample, irrespective of estimator and outcome. Moreover, in the FE-IV model, none of the endowment covariance estimates related to father's smoking are statistically significant, with the chi-square statistic with two degrees of freedom on the smoking- $\mu$ correlations being 2.13 , and the $t$-statistic on the smoking- $\phi$ correlation being 0.89. In the MCS sample, instead, father's smoking does have detrimental associations with both birth outcomes ( -40 grams and -0.93 grams per week on birth weight and fetal growth, respectively). But these effects are tenuous, as they emerge only in cross-sectional models which do not control for family-specific unobservable components or for intrafamily sequential responses.

An alternative way of using father's smoking in our context is as an instrumental variable for maternal smoking rather than as a direct input in the infant health production function (1). This may be justified by measurement error problems (although, in the BHPS, mother's smoking has not been collected retrospectively) which, in fixed effects models, might accentuate the attenuation bias in the maternal smoking effect (Griliches 1979). This instrumentation can be justified on the basis that there might be strong positive marital sorting on smoking habits (Kurzban and Weeden 2005), and that smoking by a pregnant woman's partner is likely to be a key predictor of her current smoking status (Penn and Owen 2002). If this is the case, having a partner who smokes may, for instance, affect the probability of quitting or starting smoking during pregnancy. In the spirit of first-stage regressions, we calculated odds ratios along a number of traits for couples in the BHPS and MCS samples. For a smoking woman in the BHPS sample, the odds of being married to a smoking partner are 9.6 times $(t$-value=10.51) greater than those of being matched to a partner who does not smoke. This odds ratio is virtually identical

\footnotetext{
${ }^{30} \mathrm{~A}$ large medical literature has documented the health risks associated with exposure to environmental tobacco smoke or passive smoking, especially among children (e.g., Gergen et al. 1998; Lam et al. 2001).
} 
to that on age and almost three times larger than the corresponding one on education (for which we have an odds ratio of $3.6, t$-value $=7.53$ ). These results emerge also after a standard set of demographic controls are held constant, and are found in the MCS sample too. Smoking status of the male partner therefore is strongly positively associated with mother's smoking. Appendix C shows the additional population moments that characterize the two-child family case in the presence of one input and one new instrumental variable (which is allowed to be correlated with $\mu$ but, by definition, is uncorrelated with $\phi$ for all birth orders).

The FE-IV results obtained from regressions on the two-child family subsample of the BHPS and in which father's prenatal smoking is used as the additional instrumental variable are reported in Table 6 (column (ii)). Because we have a parsimonious specification in which maternal employment status has been redefined as a dichotomous variable, we also present the estimates from FE-IV models which exclude father's smoking and do not treat it as an instrumental variable (column (i)). As revealed by the overidentifying restriction tests at the bottom of the table, we cannot reject father's smoking status as a valid instrument for mother's smoking. The coefficients on all the endowment covariances and intrafamily responses remain essentially the same as those presented above, as do our inferences about the other (not reported) inputs. Interestingly, the estimated impact of mother's smoking on both birth outcomes increases in absolute value by about 20 percent, while that of job interruptions rises by nearly one third. These results are consistent with the presence of measurement error in the mother's smoking variable. Therefore, although the role of father's smoking as a direct input is arguably negligible, its correlation with maternal smoking makes it a powerful instrument.

\section{E. Selectivity Issues}

In line with the dynamic model of Section 4, our results indicate that intrafamily resource allocations depend on child-specific endowments and that prenatal investment decisions on higher-order pregnancies are affected by the idiosyncratic endowments of all prior children. The identification of such responses relies on the estimation of fixed-effects instrumentalvariables sibling models, which make use of longitudinal information on multiple children within a family. If the decision of having another birth depends on the child-specific endowments of all prior births (for instance, women with better endowed children may be more inclined to have additional births), then the sample of mothers with two or more children that is required to estimate FE-IV models is likely to be selective. 
To ascertain the extent of this selectivity issue, we distinguished NSFG families with only one child from families with two or more children. Conditional on having one child, we then tried to see whether or not the probability of having at least one additional birth differs by the firstborn's observed birth weight (fetal growth) after controlling for a set of standard demographic variables, such as childs sex, and mother's age, education and race. ${ }^{31}$ The results (not shown for convenience) reveal that this type of selectivity, while it cannot be ruled out, is likely to play a very limited role. Although first born babies of mothers who had two or more children were heavier than their singleton counterparts, the difference in the effect of observed birth weight on subsequent fertility is always very small and statically significant only in the case of birth weight, but not in the case of fetal growth or low birth weight as measures of observed human capital at birth. For example, if a woman has a first baby who weighs 500 grams more than the average first child in the population (which, in the NSFG sample, roughly corresponds to a sizeable increase of one standard deviation over the mean birth weight), she is only 1.1 percentage points more likely to have an additional birth than the mother of the average-weight child (an increase of 1.6 percent). When we look at the fertility response to either fetal growth of the first child or to a birth weight below 2,500 grams of the first child, we find even smaller and insignificant effects on the probability of having an additional child.

A different source of selectivity is driven by censoring. Many of the mothers in our longitudinal samples who are observed with only one child might have subsequent births, but only after the end of the survey period. The estimates of the technology parameters and the dynamic effects may then change as more of such women and their children are drawn into our samples, provided they alter the existing interfamily and intrafamily heterogeneity distributions. Accordingly, we re-estimated the OLS, FE and FE-IV models for each birth outcome on a new NSFG subsample that excluded all mothers aged 34 or less at the time of interview. This new sample, which contains about one-half of the children and mothers in the original sample, should be less affected by survey censoring problems. For both birth outcomes, the FE-IV effects of the maternal smoking and labor supply are between 1 and 7 percent greater in absolute value in the new subsample than in the original sample (shown in Table 3), and the differences are never statistically significant. For example, the

\footnotetext{
${ }^{31}$ Notice that this assessment cannot be made using the first child's idiosyncratic endowment (rather than his/her observed birth weight or fetal growth), because this stochastic component can only be estimated on families with multiple children through FE sibling or FE-IV sibling procedures, unless one is willing to use cross-sectional estimates of the idiosyncratic health shocks, which ignore either or both permanent unobserved health factors that vary across families and parents' dynamic adjustments to child-specific endowments.
} 
coefficients (s.e.) on the maternal smoking variable are -0.158 (0.042) and -3.593 (1.604) for birth weight and fetal growth, respectively. This similarity holds true for the other inputs, as does the overall pattern of estimation precision. Finally, the estimates on the input- $\mu$ and input- $\phi$ correlations remain essentially the same, leaving unchanged our interpretation on parental dynamic adjustments to child-specific idiosyncratic shocks.

\section{Postnatal Investments}

Our focus so far has been on prenatal investments. In line with the discussions in Sections 2 and 3, we have documented that parents take account of previous birth outcomes by changing the choice of prenatal inputs over subsequent pregnancies. In terms of the inputs we have analyzed, and especially mother's smoking and job interruptions, our estimates reveal that parents respond to idiosyncratic endowment heterogeneity in a way that is consistent with equity concerns.

But parents make continuous postnatal investments in a child, which of course are chosen after parents have observed the idiosyncratic birth weight endowment of that child. As shown in (8), however, the impact of that endowment is hard to sign, even without efficiency motives. Both equity and efficiency considerations may drive intrahousehold allocation decisions after the birth of each child, and these will tend to have countervailing effects on birth (and later) outcomes. In addition, dynamic effects of postnatal investments cannot be identified structurally using appropriate variants of the production function framework of (2) and (3) and the moment conditions that such a structure implies (see Appendix B).

In any case, postnatal investment decisions and their consequences on early child outcomes are the subject of much social science research and have become central to many policy initiatives (see the Introduction; Cunha and Heckman [2007] and references therein). Despite the caveats we have raised, therefore, it is useful to analyze postnatal investments and, in particular, see whether equity concerns continue to prevail. It is with this focus in mind that we undertake an analysis of breastfeeding decisions (initiation and duration) using the NSFG sample. ${ }^{32}$ Our primary interest is different from what we have done so far: rather than estimating production functions as given in (2) and (3), our objective is to estimate linear resource allocation decisions similar to (12).

To do this, we first estimate $\phi_{1}$ as the residual from a birth weight FE-IV regression (as

\footnotetext{
${ }^{32}$ As mentioned in Section 2, one interesting feature of breastfeeding is that it is a child-specific investment, while other postnatal activities (such as playing, reading, and visiting museums) may not be so easily assignable to one child or the other.
} 
in Table 3, column [i]), which allow us to account for parental adjustment to endowment shocks. We then estimate the following

$$
B_{i j}=\alpha_{i 0}+\sum_{k=1}^{i} \alpha_{i k} C_{k j}+\sum_{k=1}^{i-1} \beta_{i k} \omega_{k j}+\sum_{k=1}^{i-1} \xi_{i k} B_{k j}+\lambda_{i 1} \phi_{i j}+u_{i j}
$$

where $B_{i j}$ denotes the breastfeeding decision on child (parity) $i$ in family $j, C_{k j}$ is a set of characteristics of all children alive up to child $i$ (e.g., sex), $\omega_{k j}$ and $B_{k j}$ indicate child $k$ 's birth weight and breastfeeding status, respectively, for all children preceding child $i$, $\phi_{i j}$ is child $i$ 's idiosyncratic endowment, and $u_{i j}$ is an i.i.d. error term. By estimating this relationship separately for children of different parity, we allow all parameters to differ across siblings according to their birth order. Notice that in the case of the first child, neither birth weight nor breastfeeding status of earlier children can be accounted for and, thus, equation (15) boils down to (12). Since we do not have time varying (child-specific) information on $y$, which is part of the allocation rule (12) and its higher parity counterparts, we also include maternal age at birth and its square and indicators of mother's education and race.

Similar reduced-form specifications have been estimated by Rosenzweig (1986) and Rosenzweig and Wolpin (1988). The procedure used in Datar et al. (2006) instead is different, as it excludes child-specific endowment shocks and considers only observed childspecific birth weights as proxy measures of child endowment, net of mother's fixed effects, child and family characteristics and endogenous prenatal inputs. ${ }^{33}$ Following the discussion of Section 4 , a negative relationship between $\phi_{i}$ and $B_{i}$ (i.e., negative values of $\lambda_{1}$ ) and a positive relationship between $B_{i}$ and previous children's birth weight (i.e., a positive value of $\beta_{1}$ for the second child, and positive values of $\beta_{1}$ and $\beta_{2}$ for the third child), and previous children's breastfeeding status (i.e., a positive value of $\xi_{1}$ for the second child, and positive values of $\xi_{1}$ and $\xi_{2}$ for the third child) will reveal evidence of equity concerns.

The OLS estimates of (15) are reported in Table 7. The first row shows that $\lambda_{1}$ is always negative and statistically significant (except in the case of breastfeeding duration for third born children). The magnitude of such estimates, however, is very small. For example, an unexpected additional 100 grams at birth for the first child (which corresponds to one extra week of gestation at least) decreases the likelihood of breastfeeding that child by only 0.3 percentage points (representing a decline of less than 1 percent over the average)

\footnotetext{
${ }^{33}$ Excluding the vector of shocks $\phi_{i j}$ from (15) leads to estimates of $\beta$ that are very similar to those presented by Datar et al. (2006) for both breastfeeding decisions, even without accounting for prenatal inputs. Again, these are quantitatively small but, as shown in (13) and (14), cannot be taken to infer equity-efficiency motives in parents' allocative decisions.
} 
and reduces breastfeeding duration by 1 day (far less than a 1 percent reduction). Results for the second child are slightly larger, although they still imply relatively modest effects. We also find a positive relationship between breastfeeding decisions on child $i$ and previous children's birth weight $\left(\beta_{1}\right.$ and $\left.\beta_{2}\right)$ and breastfeeding status $\left(\xi_{1}\right.$ and $\left.\xi_{2}\right)$.

Mothers, therefore, appear to respond to endowment shocks across children while making their postnatal breastfeeding decisions. As in the case of prenatal investments, such responses are in line with a notion of intrafamily resource allocations motivated by equity considerations, even though the reduced-form nature of the analysis does not fully warrant this interpretation. In addition, albeit statistically significant, the estimated breastfeeding responses are quantitatively small and may therefore have limited policy relevance. Because of the identification problems we have emphasized in relation to the analysis of all postnatal investments, our results are only suggestive and, inevitably, more research on these issues is needed.

\section{Conclusion}

This paper makes a number of contributions to the literature on intrahousehold resource allocation decisions. We structurally estimate the impact of prenatal inputs on infant health production functions which allow for within-family and across-family variation in health endowments and for parental adjustments to idiosyncratic health shocks of their children. Using economic theory, we suggest an interpretation of parents' dynamic adjustments in terms of equity/efficiency arguments. We also consider postnatal investments and their role in shaping intrahousehold allocations by modeling their responses to idiosyncratic health shocks at birth. The analysis is performed on two countries (the United States and Britain) with three large-scale representative samples, which have different relative advantages and complementarities.

Our estimates indicate that maternal smoking during pregnancy reduces birth weight by 140-160 grams in the US sample and by 190 grams in the British sample and reduces fetal growth by about 4 grams per week in both countries. Work interruptions before birth are beneficial, especially if taken in the last two months of pregnancy. Their positive impact, however, is only one-half and one-quarter of the negative effect of smoking on birth weight and fetal growth respectively among US mothers. Longer leaves appear to be healthful for British babies (with an effect on birth outcomes that is comparable to the effect of smoking in absolute value), a result that perhaps points at the role played by longer maternity leaves in Britain over the sample period. There is a fair amount 
of estimate heterogeneity along mother's age at birth and education. For example, the negative effect of smoking is observed mainly among children whose mothers gained low educational qualifications or were relatively young at the birth of their first child, while work interruptions appear to improve birth outcomes more for low-education mothers, especially among British women.

The impact of father's smoking on birth outcomes represents at best only one-fifth of the effect of mother's smoking, and becomes negligible when intrafamily health heterogeneity is taken into account. So, having two smoking parents does not translate into a double health jeopardy for the infant, at least in terms of birth outcomes. But, when father's smoking is treated as an instrumental variable for maternal smoking rather than a direct input, the effect of mother's smoking on birth outcomes becomes 20 percent greater in absolute value and the impact of mother's time off work increases by another 30 percent. This finding, which is consistent with the presence of measurement error in the mother's smoking variable, suggests that our earlier estimates of the effect of maternal smoking may be lower bounds.

The results also indicate that there are child-specific components of unobservables that sequentially affect parental behavior. In particular, there is evidence of parents' choice over prenatal inputs across siblings that is driven by equity considerations. This is important for its distributional and policy consequences. If families have equal concerns towards their offspring, the socioeconomic gradient in outcomes observed at later points of children's life may be driven more by variation between families than by variation within families. With parents caring for equal opportunities given to all their children, transfer programs and information campaigns directed towards particular types of household members (e.g., infants and pregnant working women) in particular households (e.g., young, poor or less educated) are likely to be more effective than in economies in which parental investments tend to exacerbate differences across siblings. This finding will also have implications for the analysis of other later outcomes, such as child development and education, for which intrahousehold allocations are conceivably responsive to child idiosyncratic endowments.

The finding that such unmeasured endowments are dynamically correlated to parental inputs has also salient econometric implications, as it suggests that neither within-family differencing nor instrumental variables techniques applied to cross-sectional data can in isolation address the issues implied by dynamic family behavior. As more large-scale surveys tend to include multiple siblings from the same household, it should be increasingly straightforward to combine within-mother estimators with instrumental variables. 
The importance of parents' dynamic responses to child-specific endowments emerges also from the analysis of postnatal investments (breastfeeding), even though in this case we do not estimate the impact of such investments on child outcomes but, in a reducedform fashion, their responsiveness to child-specific endowments. Maternal breastfeeding decisions appear to respond to unanticipated outcomes in a way that is consistent with equity arguments. In general, however, the magnitude of these effects is quantitatively small. Whether equity concerns prevail in subsequent parental decisions (e.g., playing, tutoring, and educational expenditures) is of paramount importance for policy and, to a large extent, remains to be seen.

Several extensions of the analysis would be desirable. First, and as just mentioned, other postnatal outcomes and parental decisions could be analyzed. This would allow us to test if equity concerns apply to child outcomes that extend beyond birth, such as cognitive/noncognitive development and schooling as well as child care decisions and family disruptions (Cunha et al. 2006). Such outcomes and investments require a different conceptual setup from the one used here and would have to hinge on different identifying restrictions. Second, estimating our model on data from developing countries could provide new assessments of issues related to son preference and intrafamily resource distribution (Oster 2005). Third, in the context of prenatal inputs and infant health production functions, combining information from birth registers, which provide nearly exact knowledge of moments of the marginal distribution of birth weight, with our longitudinal samples is likely to improve accuracy of estimation (Imbens and Lancaster 1994). This is likely to be important especially in the case of the relatively small BHPS sample, for which the gains from the use of marginal information could be substantial. Finally, formulating and estimating a fully structural model (e.g., Keane and Wolpin 2001; Aguirregabiria and Mira 2007; Bernal and Keane 2008) in which parents optimally choose resources to allocate to their offspring with endogenous fertility and birth spacing would enormously enhance our insights into the role of the family in the intergenerational transmission of human capital and our understanding of whether such intrafamily allocations are socially efficient. 


\section{Appendix A}

\section{Additional Moment Equations in the Three-Child Family Case}

Besides (2) and (3), there is a third production function for the third child, which in the case of only one input, is given by: $h_{3}=\gamma x_{3}+\mu+\phi_{3}$. Using (2) and (3) and this new expression, the extra moment equations that characterize this economy in addition to those reported in Section 3 are:

$$
\begin{aligned}
\sigma_{h_{3}}^{2} & =\gamma^{2} \sigma_{x_{3}}^{2}+\gamma \sigma_{x_{3} \mu}+\sigma_{\mu}^{2}+\sigma_{\phi_{3}}^{2}, \\
\sigma_{h_{1} h_{3}} & =\gamma^{2} \sigma_{x_{1} x_{3}}^{2}+\gamma\left(\sigma_{x_{1} \mu}+\sigma_{x_{3} \mu}\right)+\gamma \sigma_{x_{3} \phi_{1}}+\sigma_{\mu}^{2}, \\
\sigma_{h_{2} h_{3}} & =\gamma^{2} \sigma_{x_{2} x_{3}}+\gamma\left(\sigma_{x_{2} \mu}+\sigma_{x_{3} \mu}\right)+\gamma \sigma_{x_{3} \phi_{2}}+\sigma_{\mu}^{2}, \\
\sigma_{h_{3} x_{1}} & =\gamma \sigma_{x_{1} x_{3}}+\sigma_{x_{1} \mu}, \\
\sigma_{h_{3} x_{2}} & =\gamma \sigma_{x_{2} x_{3}}+\sigma_{x_{2} \mu}, \\
\sigma_{h_{3} x_{3}} & =\gamma \sigma_{x_{3}}^{2}+\sigma_{x_{3} \mu}, \\
\sigma_{h_{1} x_{3}} & =\gamma \sigma_{x_{1} x_{3}}+\sigma_{x_{3} \mu}+\sigma_{x_{3} \phi_{1}}, \\
\sigma_{h_{2} x_{3}} & =\gamma \sigma_{x_{2} x_{3}}+\sigma_{x_{3} \mu}+\sigma_{x_{3} \phi_{2}} .
\end{aligned}
$$

As pointed out in Section 2, we have eight additional equations with only four additional unknown parameters $\left(\sigma_{x_{3} \mu}, \sigma_{x_{3} \phi_{2}}, \sigma_{x_{3} \phi_{1}}, \sigma_{\phi_{3}}^{2}\right)$, so that the system is overidentified.

\section{Appendix B}

\section{Moment Equations in the Case of Postnatal Investment}

As in other models of postnatal investments in a child (e.g., Rosenzweig and Schultz 1983b; Rosenzweig and Wolpin 1988), we also emphasize the importance of characteristics (inputs and endowments) of children born prior to that child. We thus slightly modify the production functions (2) and (3) in a three-child economy with only one input as follows (and, to keep notation simple, other child-specific stochastic terms which could legitimately affect $h_{i}$ are excluded):

$$
\begin{aligned}
& h_{1}=\gamma b_{1}+\mu+\phi_{1}, \\
& h_{2}=\gamma b_{2}+\delta b_{1}+\mu+\phi_{2}+\eta \phi_{1}, \\
& h_{3}=\gamma b_{3}+\delta b_{2}+\alpha b_{1}+\mu+\phi_{3}+\eta \phi_{2}+\vartheta \phi_{1},
\end{aligned}
$$

where $b$ is a postnatal input (such as breastfeeding), and each of the idiosyncratic endowments $\phi_{i}(i=1,2,3)$ is known to parents when they make decisions on $b_{i}$ as well as when they make decisions of subsequent children. Importantly, and differently from the production functions (5a) and (5b) formulated in Section 4, the expressions (A.1)-(A.3) treat postnatal investments independently of prenatal investments ( $x_{i}$ in the notation used in the text) and are not affected by observed birth outcomes at each parity (e.g., birth weight). If we allowed for such correlations to be nonzero, the two-child family case with one postnatal input and one prenatal input would then be characterized by 15 equations and 18 parameters, and, without further orthogonality restrictions, it would not be identified. In any case, as the discussion below should clarify, the system (A.1)-(A.3) is underidentified even when such simplifying orthogonality conditions are imposed. 
The moment conditions that characterize the two-child case (A.1)-(A.2) are given by:

$$
\begin{aligned}
\sigma_{h_{1}}^{2}= & \gamma^{2} \sigma_{b_{1}}^{2}+\gamma \sigma_{b_{1} \mu}+\gamma \sigma_{b_{1} \phi_{1}}+\sigma_{\mu}^{2}+\sigma_{\phi_{1}}^{2} \\
\sigma_{h_{2}}^{2}= & \gamma^{2} \sigma_{b_{2}}^{2}+\delta^{2} \sigma_{b_{1}}^{2}+\gamma \delta \sigma_{b_{1} b_{2}}+\gamma \sigma_{b_{2} \mu}+\delta \sigma_{b_{1} \mu}+\gamma \sigma_{b_{2} \phi_{2}}+\gamma \eta \sigma_{b_{2} \phi_{1}}+\delta \eta \sigma_{b_{1} \phi_{1}} \\
& +\eta \sigma_{\phi_{1} \phi_{2}}+\sigma_{\mu}^{2}+\sigma_{\phi_{2}}^{2}+\eta^{2} \sigma_{\phi_{1}}^{2} \\
\sigma_{h_{1} h_{2}}= & \gamma^{2} \sigma_{b_{1} b_{2}}+\gamma \delta \sigma_{b_{1}}^{2}+(\gamma+\delta) \sigma_{b_{1} \mu}+\gamma \sigma_{b_{2} \mu}+\gamma \eta \sigma_{b_{1} \phi_{1}}+\gamma \sigma_{b_{2} \phi_{1}}+\delta \sigma_{b_{1} \phi_{1}} \\
& +\sigma_{\phi_{1} \phi_{2}}+\sigma_{\mu}^{2}+\eta \sigma_{\phi_{1}}^{2} \\
\sigma_{h_{1} b_{1}}= & \gamma \sigma_{b_{1}}^{2}+\sigma_{b_{1} \mu}+\sigma_{b_{1} \phi_{1}} \\
\sigma_{h_{2} b_{1}}= & \gamma \sigma_{b_{1} b_{2}}+\delta \sigma_{b_{1}}^{2}+\sigma_{b_{1} \mu}+\eta \sigma_{b_{1} \phi_{1}} \\
\sigma_{h_{1} b_{2}}= & \gamma \sigma_{b_{1} b_{2}}+\sigma_{b_{2} \mu}+\sigma_{b_{2} \phi_{1}} \\
\sigma_{h_{2} b_{2}}= & \gamma \sigma_{b_{2}}^{2}+\delta \sigma_{b_{1} b_{2}}+\sigma_{b_{2} \mu}+\sigma_{b_{2} \phi_{2}}+\eta \sigma_{b_{2} \phi_{1}} .
\end{aligned}
$$

From these seven moment equations, it is not possible to recover the twelve unknown parameters that characterize the population of two-child families $\left\{\gamma, \delta, \eta, \sigma_{\mu}^{2}, \sigma_{\phi_{1}}^{2}, \sigma_{\phi_{2}}^{2}, \sigma_{b_{1} \mu}, \sigma_{b_{2} \mu}, \sigma_{b_{1} \phi_{1}}, \sigma_{b_{2} \phi_{2}}\right.$, $\left.\sigma_{b_{2} \phi_{1}}, \sigma_{\phi_{1} \phi_{2}}\right\}$. Notice that even if $\delta=\eta=0$ (that is, prior children's endowments and inputs do not directly affect subsequent children's human capital production) or if $\sigma_{\phi_{1} \phi_{2}}=0$ (that is, the child-specific endowment shocks are not correlated even if endowments are observed), the system is still underidentified.

Considering the three-child family case and embedding (A.3) into the system lead to following eight additional moment equations:

$$
\begin{aligned}
\sigma_{h_{3}}^{2}= & \gamma^{2} \sigma_{b_{3}}^{2}+\delta^{2} \sigma_{b_{2}}^{2}+\alpha^{2} \sigma_{b_{1}}^{2}+\gamma \delta \sigma_{b_{2} b_{3}}+\alpha \gamma \sigma_{b_{1} b_{3}}+\alpha \delta \sigma_{b_{1} b_{2}}+\gamma \sigma_{b_{3} \mu}+\delta \sigma_{b_{2} \mu}+\alpha \sigma_{b_{1} \mu} \\
& +\gamma \sigma_{b_{3} \phi_{3}}+\gamma \eta \sigma_{b_{3} \phi_{2}}+\gamma \vartheta \sigma_{b_{3} \phi_{1}}+\delta \eta \sigma_{b_{2} \phi_{2}}+\delta \vartheta \sigma_{b_{2} \phi_{1}}+\alpha \vartheta \sigma_{b_{1} \phi_{1}}+\eta \vartheta \sigma_{\phi_{1} \phi_{2}} \\
& +\vartheta \sigma_{\phi_{1} \phi_{3}}+\eta \sigma_{\phi_{2} \phi_{3}}+\sigma_{\mu}^{2}+\sigma_{\phi_{3}}^{2}+\eta^{2} \sigma_{\phi_{2}}^{2}+\vartheta^{2} \sigma_{\phi_{1}}^{2} \\
\sigma_{h_{1} h_{3}}= & \gamma^{2} \sigma_{b_{1} b_{3}}+\gamma \delta \sigma_{b_{1} b_{2}}+\alpha \gamma \sigma_{b_{1}}^{2}+(\alpha+\gamma) \sigma_{b_{1} \mu}+\gamma \sigma_{b_{3} \mu}+\delta \sigma_{b_{2} \mu}+(\alpha+\gamma \vartheta) \sigma_{b_{1} \phi_{1}} \\
& +\gamma \sigma_{b_{3} \phi_{1}}+\delta \sigma_{b_{2} \phi_{1}}+\eta \sigma_{\phi_{1} \phi_{2}}+\sigma_{\phi_{1} \phi_{3}}+\sigma_{\mu}^{2}+\vartheta \sigma_{\phi_{1}}^{2}, \\
\sigma_{h_{2} h_{3}}= & \gamma^{2} \sigma_{b_{2} b_{3}}+\gamma \delta \sigma_{b_{2}}^{2}+\alpha \delta \sigma_{b_{1}}^{2}+\left(\alpha \gamma+\delta^{2}\right) \sigma_{b_{1} b_{2}}+\gamma \delta \sigma_{b_{1} b_{3}}+(\alpha+\delta) \sigma_{b_{1} \mu}+(\gamma+\delta) \sigma_{b_{2} \mu} \\
& +\gamma \sigma_{b_{3} \mu}+(\alpha+\delta \vartheta) \sigma_{b_{1} \phi_{1}}+(\gamma \eta+\delta) \sigma_{b_{2} \phi_{2}}+(\gamma \vartheta+\delta \eta) \sigma_{b_{2} \phi_{1}}+\gamma \eta \sigma_{b_{3} \phi_{1}}+\gamma \sigma_{b_{3} \phi_{2}} \\
& +\left(\vartheta+\eta^{2}\right) \sigma_{\phi_{1} \phi_{2}}+\eta \sigma_{\phi_{1} \phi_{3}}+\sigma_{\phi_{2} \phi_{3}}+\sigma_{\mu}^{2}+\eta \sigma_{\phi_{2}}^{2}+\eta \vartheta \sigma_{\phi_{1}}^{2}, \\
\sigma_{h_{3} b_{1}}= & \gamma \sigma_{b_{1} b_{3}}+\delta \sigma_{b_{1} b_{2}}+\alpha \sigma_{b_{1}}^{2}+\sigma_{b_{1} \mu}+\vartheta \sigma_{b_{1} \phi_{1}}, \\
\sigma_{h_{3} b_{2}}= & \gamma \sigma_{b_{2} b_{3}}+\delta \sigma_{b_{2}}^{2}+\alpha \sigma_{b_{1} b_{2}}+\sigma_{b_{2} \mu}+\eta \sigma_{b_{2} \phi_{2}}+\vartheta \sigma_{b_{2} \phi_{1}}, \\
\sigma_{h_{3} b_{3}}= & \gamma \sigma_{b_{3}}^{2} \delta \sigma_{b_{2} b_{3}}+\alpha_{b_{1} b_{3}}+\sigma_{b_{3} \mu}+\sigma_{b_{3} \phi_{3}}+\eta \sigma_{b_{3} \phi_{2}}+\vartheta \sigma_{b_{3} \phi_{1}}, \\
\sigma_{h_{1} b_{3}}= & \gamma \sigma_{b_{1} b_{3}}+\sigma_{b_{3} \mu}+\sigma_{b_{3} \phi_{1}} \\
\sigma_{h_{2} b_{3}}= & \gamma \sigma_{b_{2} b_{3}}+\delta \sigma_{b_{1} b_{3}}+\sigma_{b_{3} \mu}+\sigma_{b_{3} \phi_{2}}+\eta \sigma_{b_{3} \phi_{1}} .
\end{aligned}
$$

Despite the addition of these eight equations, we have nine extra parameters to estimate $\left(\alpha, \vartheta, \sigma_{\phi_{3}}^{2}\right.$, $\sigma_{b_{3} \mu}, \sigma_{b_{3} \phi_{3}}, \sigma_{b_{3} \phi_{2}}, \sigma_{b_{3} \phi_{1}}, \sigma_{\phi_{1} \phi_{3}}, \sigma_{\phi_{2} \phi_{3}}$ ). This means that the system is underidentified (with fifteen equations and twenty-one parameters). Even if prior children's endowments are assumed not to affect subsequent siblings' human capital (that is, $\eta=\vartheta=0$ ) and child-specific endowments shocks are uncorrelated (i.e., $\sigma_{\phi_{1} \phi_{2}}=\sigma_{\phi_{1} \phi_{3}}=\sigma_{\phi_{2} \phi_{3}}=0$ ), the system on three-child families is still underidentified. Its identification will rest on other (even stronger) restrictions, e.g., the assumption that inputs used to produce prior children's human capital cannot affect outcomes of subsequent children (i.e., both $\alpha$ and $\delta$ are zero) or, if they do affect outcomes, that their effects are the same across children $(\alpha=\delta)$. 


\section{Appendix C}

\section{Population Moments in the Two-Child Family Case with One Input and One Instrument}

Consider the production functions (2)-(3) that characterize the two-child family case. In that context, a child-specific instrumental variable, $z_{i}(i=1,2)$, is supposed to affect $h_{i}$ only through its correlation with $x_{i}$ and $\mu$ but not directly. That is, $z_{i}$ enters in neither (2) nor (3), but its correlations with $h_{i}$ place further moment restrictions on the population and represent other orthogonality conditions. The new moment restrictions, which add to those already shown in Section 3.2, are:

$$
\begin{aligned}
\sigma_{h_{1} z_{1}} & =\gamma \sigma_{x_{1} z_{1}}+\sigma_{z_{1} \mu} \\
\sigma_{h_{2} z_{1}} & =\gamma \sigma_{x_{2} z_{1}}+\sigma_{z_{1} \mu} \\
\sigma_{h_{1} z_{2}} & =\gamma \sigma_{x_{1} z_{2}}+\sigma_{z_{2} \mu} \\
\sigma_{h_{2} z_{2}} & =\gamma \sigma_{x_{2} z_{2}}+\sigma_{z_{1} \mu} .
\end{aligned}
$$

These are four new moment restrictions with only two additional parameters, $\sigma_{z_{1} \mu}$ and $\sigma_{z_{2} \mu}$. (The parameter $\gamma$ entered also the other moment restrictions which have been presented in the text.) Thus, in comparison to the case discussed in the text, we have eleven equations (seven of which coincide with those shown in Section 3, and the other four are shown above) and nine parameters, leaving us with two overidentifying restrictions. In the case of three-child families, there are nine extra equations to be added to the original 15 equations implied by a production function with one input (see Appendix A). Since only three parameters $\left(\sigma_{z_{1} \mu}, \sigma_{z_{2} \mu}, \sigma_{z_{3} \mu}\right.$ are added to the original eleven parameters, this means we have 10 overidentifying restrictions to add. In the empirical analysis reported in Section 6.D, however, we use the subsample with two-child families only. 


\section{References}

Abrevaya, Jason. 2006. "Estimating the Effect of Smoking on Birth Outcomes Using a Matched Panel Data Approach." Journal of Applied Econometrics 21 (March): 489-519.

Abrevaya, Jason and Christian Dahl. 2005. "The Effects of Smoking and Prenatal Care on Birth Outcomes: Evidence from Quantile Estimation on Panel Data." Journal of Business and Economic Statistics (forthcoming).

Aguirregabiria, Victor, and Pedro Mira. 2007. "Sequential Estimation of Dynamic Discrete Games." Econometrica 75 (January): 1-53.

Alberry, Michael, and Peter Soothill. 2007. "Management of Fetal Growth Restriction." Archives of Disease in Childhood 92 (January): F62-F67.

Almond, Douglas, Kenneth Y. Chay, and David S. Lee. 2005. "The Costs of Low Birth Weight." Quarterly Journal of Economics 120 (August): 1031-83.

Amato, Paul R. 2000. "The Consequences of Divorce for Adults and Children." Journal of Marriage and the Family 62 (November): 1269-87.

Anderson, J.W., B.M. Johnstone, and D.T. Remley. 1999. "Breast-feeding and Cognitive Development: A Meta-Analysis." American Journal of Clinical Nutrition 70 (October): 525-35.

Aunola, Kaisa, and Jari-Erik Nurmi. 2005. "The Role of Parenting Styles in Children's Problem Behavior." Child Development 76 (November/December): 1144-59.

Baker, Michael, and Kevin Milligan (2008). "Maternal Employment, Breastfeeding, and Health: Evidence from Maternity Leave Mandates." Journal of Health Economics 27 (July): 871-87.

Barker, David J.P. 1995. "Fetal Origins of Coronary Heart Disease." British Medical Journal 311 (July): 171-74.

Bartley M., Christine Power, D. Blane, and G. Davey Smith. 1994. "Birthweight and Later Socioeconomic Disadvantages: Evidence from the 1958 British Cohort Study." British Medical Journal 309 (December): 1475-78.

Becker, Gary S., and Nigel Tomes. 1976. "Child Endowments and the Quantity and Quality of Children." Journal of Political Economy 84 (August, part 2): S143-S162.

Behrman, Jere R. 1997. "Intrahousehold Distribution and the Family." In Handbook of Family Economics edited by Mark R. Rosenzweig and Oded Stark. Amsterdam: Elsevier Science.

Behrman, Jere R., Robert A. Pollak, and Paul Taubman. 1982. "Parental Preferences and Provision for Progeny." Journal of Political Economy 90 (February): 52-73.

Behrman, Jere R., and Mark R. Rosenzweig. 2004. "Returns to Birthweight." Review of Economics and Statistics 86 (May): 586-601.

Belsky, Jay, and Fearon R.M. Pasco. 2004. "Exploring Marriage-Parenting Typologies, Their Contextual Antecedents and Developmental Sequalae." Development and Psychopathology 16 (September): 501-24.

Belsky, Jay, Edward Melhuish, Jacqueline Barnes, Alastair H. Leyland, Helena Romaniuk, and the National Evaluation of Sure Start Research Team. 2006. "Effects of Sure Start Local Programmes on Children and Families: Early Findings from a Quasi-Experimental, Cross Sectional Study." British Medical Journal 332 (June): 1476-81. 
Bergstrom, Theodore C. 1989. "A Fresh Look at the Rotten Kid Theorem - And Other Household Mysteries." Journal of Political Economy 97 (October): 1138-59.

Bernal, Raquel, and Michael P. Keane. 2008. "Quasi-Structural Estimation of a Model of Child Care Choices and Child Cognitive Ability Production." Journal of Econometrics, forthcoming.

Black, Sandra E., Paul J. Devereux, and Kjell G. Salvanes. 2007. "From the Cradle to the Labor Market? The Effect of Birth Weight on Adult Outcomes." Quarterly Journal of Economics 122 (February): 409-39.

Blau, David M. 1999. "The Effect of Child Care Characteristics on Child Development." Journal of Human Resources 34 (Fall): 786-822. (a)

Blau, David M. 1999. "The Effect of Income on Child Development." Review of Economics and Statistics 81 (May): 261-76. (b)

Bonzini, Matteo, David Coggon, and Keith T. Palmer. 2007. "Risk of Prematurity, Low Birthweight and Pre-eclampsia in Relation to Working Hours and Physical Activities: A Systematic Review." Occupational and Environment Medicine 64 (April): 228-43.

Bouckaert, 2000. "Smoking During Pregnancy: Foetal Growth Retardation and Other Risks for the Newborn." Statistics in Medicine 19 (January): 239-254.

Brooks-Gunn, Jeanne, Wen-Jui Han, and Jane Waldfogel. 2002. "Maternal Employment and Child Cognitive Outcomes in the First Three Years of Life: The NICHD Study of Early Child Care." Child Development 73 (July/August): 1052-72.

Butler, Neville R., and Eva D. Alberman. 1969. Perinatal Problems. The Second Report of the 1958 British Perinatal Mortality Survey. London: E. and S. Livingstone Ltd.

Carneiro, Pedro, and James Heckman. 2003. "Human Capital Policy." In B. Friedman (ed.) Inequality in America: What Role for Human Capital Policies. MIT Press: Cambridge.

Case, Anne, Angela Fertig, and Christina Paxson. 2005. "The Lasting Impact of Childhood Health and Circumstance." Journal of Health Economics 24 (March): 365-89.

Case, Anne, Darren Lubotsky, and Christina Paxson. 2002. "Economic Status and Health in Childhood: The Origins of the Gradient." American Economic Review 92 (December): 1308-34.

Croteau, Agathe, Marcoux, Sylvie, and Chantal Brisson. 2006. "Work Activity in Pregnancy, Preventive Measures, and the Risk of Delivering a Small-for-Gestational-Age Infant." American Journal of Public Health 96 (May): 846-55.

Cunha, Flavio, and James Heckman. 2007. "The Technology of Skill Formation." American Economic Review Papers and Proceedings 97 (May): 31-47.

Cunha, Flavio, James J. Heckman, Lance J. Lochner, Dimitriy V. Masterov. 2006. "Interpreting the Evidence on Life Cycle Skill Formation." In Handbook of the Economics of Education edited by Eric A. Hanushek and Finis Welch. Amsterdam: Elsevier Science.

Currie, Janet. 2004. "Child Research Comes of Age." Canadian Journal of Economics 37 (August): 509-27.

Currie, Janet, and Nancy Cole. 1991. "Does Participation in Entitlement Programs Increase Birth Weight?" NBER Working Paper No. 3832. Cambridge, MA: National Bureau of Economic Research. 
Currie, Janet, and Nancy Cole. 1993. "Welfare and Child Health: The Link Between AFDC Participation and Birth Weight." American Economic Review 83 (September): 971-85.

Currie, Janet, and Jonathan Gruber. 1996. "Saving Babies: The Efficacy and Cost of Recent Changes in the Medicaid Eligibility of Pregnant Women." Journal of Political Economy 104 (December): 1263-96.

Currie, Janet, and Rosemary Hyson. 1999. "Is the Impact of Health Shocks Cushioned by Socioeconomic Status? The Case of Low Birthweight." American Economic Review Papers and Proceedings 82 (May): 245-50.

Currie, Janet, and Duncan Thomas. 1995. "Does Head Start Make a Difference?" American Economic Review 85 (June): 341-64.

Currie, Janet, and Duncan Thomas. 2000. "School Quality and the Longer-Term Effects of Head Start" Journal of Human Resources 35 (Fall): 755-74.

Dahl, Gordon, and Lance Lochner. 2005. "The Impact of Family Income on Child Achievement." NBER Working Paper No. 11279. Cambridge, MA: National Bureau of Economic Research.

Datar, Ashlesha, Kilburn, M. Rebecca, and David S. Loughran. 2006. "Health Endowments and Parental Investments in Infancy and Early Childhood." RAND Labor and Population Working Paper WR-367. RAND: Santa Monica, CA.

Der, G., Batty, G.D., and I. J. Deary. 2006. "Effect of Breastfeeding on Intelligence in Children: Prospective Study, Sibling Pairs Analysis, and Meta-Analysis." British Medical Journal 333 (November): 945-48.

Dougherty, C.R., and A.D. Jones. 1982. "The Determinants of Birth Weight." American Journal of Obstetrics and Gynecology, 144 (February): 190-200.

Duncan, Greg J., and Jeanne Brooks-Gunn. 1997. Consequences of Growing Up Poor. Russell Sage Foundation: New York.

Evans, William N., and Diana S. Lien. 2005. "The Benefits of Prenatal Care: Evidence from the PAT Bus Strike." Journal of Econometrics 125 (March/April): 207-39.

Evans, William N., and Jeanne S. Ringel. 1999. "Can Higher Cigarette Taxes Improve Birth Outcomes." Journal of Public Economics 72 (April): 135-54.

Feinstein, Leon. 2003. "The Effects of Maternal Employment on Child Development in the UK." Economica 70 (February): 73-98.

Fryer, Roland G. Jr., and Steven D. Levitt. 2004. "The Causes and Consequences of Distinctively Black Names." Quarterly Journal of Economics 119 (August): 767-805.

Gergen Peter J., Jean A. Fowler, Kurt R. Maurer, William W. Davis, and Mary D. Overpeck. 1998 "The Burden of Environmental Tobacco Smoke Exposure on the Respiratory Health of Children 2 Months Through 5 Years of Age in the United States: Third National Health and Nutrition Examination Survey, 1988 to 1994." Pediatrics 101 (February): e8.

Geronimus, Arline T., and Sanders Korenman. 1993. "Maternal Youth or Family Background? On the Health Disadvantages of Infants with Teenage Mothers." American Journal of Epidemiology 137 (January): 213-25.

Goldenberg, Robert L. 2002. "The Management of Preterm Labor." Obstetrics and Gynecology 100 (November): 1020-1037. 
Griliches, Zvi. "Sibling Models and Data in Economics: Beginnings of a Survey." Journal of Political Economy 87 (October, part 2): S37-S64.

Grossman, Michael, and Theodore J. Joyce. 1990. "Unobservables, Pregnancy Resolutions, and Birth Weight Production Functions." Journal of Political Economy 98 (October): 983-1007.

Haveman, Robert, and Barbara Wolfe. 1995. "The Determinants of Children Attainments: A Review of Methods and Findings." Journal of Economic Literature 33 (December): 1829-78.

Heckman, James J. 2000. "Policies to Foster Human Capital." Research in Economics 54 (March): 3-56.

Heckman, James J. 2008. "Schools, Skills, and Synapses." NBER Working Paper No. 14064. Cambridge, MA: National Bureau of Economic Research.

Hennessy, Enid, and Eva Alberman. 1998. "Intergenerational Influences Affecting Birth Outcome. I. Birthweight for Gestational Age in the Children of the 1958 British Birth Cohort." Paediatric and Perinatal Epidemiology 12 (July, Suppl. 1): 45-60.

Hofferth, Sandra L. 2006. "Residential Father Family Type and Child Well-Being: Investment versus Selection." Demography 43 (February): 53-77.

Iams, Jay D. 2003. "Prediction and Early Detection of Preterm Labor." Obstetrics and Gynecology 101 (February): 402-412.

Illsley, Raymond. 2002. "A City's Schools: From Inequality of Input to Inequality of Outcome." Oxford Review of Education 28 (December): 427-445.

Imbens, Guido W., and Tony Lancaster. 1994. "Combining Micro and Macro Data in Microeconometric Models." Review of Economic Studies 61 (October): 655-680.

Ip, Stanley, Chung, Mei, Raman, Gowri, Chew, Priscilla, Magula, Nombulelo, DeVine, Deidre, Trikalinos, Thomas, and Joseph Lau. 2007. Breastfeeding and Maternal and Infant Health Outcomes in Developed Countries. Agency for Healthcare Research and Quality Publication 07E007.

James-Burdumy, Susanne. 2005. "The Effect of Maternal Labor Force Participation on Child Development." Journal of Labor Economics 23 (January): 177-211.

Keane, Michael P., and Kenneth I. Wolpin. 2001. "The Effect of Parental Transfers and Borrowing Constraints on Education Attainment." International Economic Review 42 (November): 1051-103.

Kramer, Michael S. 1987. "Intrauterine Growth and Gestational Duration Determinants." Pediatrics 80 (October): 502-11.

Kramer, Michael S., Beverley Chalmers, Ellen D. Hodnett, Zinaida Sevkovskaya, Irina Dzikovich, Stanley Shapiro, Jean-Paul Collet, Irina Vanilovich, Irina Mezen, Thierry Ducruet, George Shishko, Vyacheslav Zubovich, Dimitri Mknuik, Elena Gluchanina, Viktor Dombrovskiy, Anatoly Ustinovitch, Tamara Kot, Natalia Bogdanovich, Lydia Ovchinikova, Elisabet Helsing, for the PROBIT Study Group. 2001. "Promotion of Breastfeeding Intervention Trial (PROBIT). A Randomized Trial in the Republic of Belarus." Journal of the American Medical Association 285 (January): 413-20.

Kurzban, Robert, and Jason Weeden. 2005. "HurryDate: Mate Preferences in Action." Evolution and Human Behavior 26 (May): 227-44. 
Lang, Janet M., Ellice Lieberman, and Amy Cohen. 1996. "A Comparison of Risk Factors for Preterm Labor and Term Small-For-Gestational-Age Birth." Epidemiology 7 (July): 369-76.

Lien, Diana S., and William N. Evans. 2005. "Estimating the Impact of Large Cigarette Tax Hikes: The Case of Maternal Smoking and Infant Birth Weight." Journal of Human Resources 40 (Spring): 373-92.

Love, E.J., and Richard A.M. Kinch. 1965. "Factors Influencing Birth Weight in a Normal Pregnancy" American Journal of Obstetrics and Gynecology 91 (October): 342-47.

Marmot, Michael. 2005. "Social Determinants of Health Inequalities." The Lancet 365 (March): 1099-104.

Mayer, Susan E. 1997. What Money Can't Buy. Harvard University Press: Cambridge, MA.

McLanahan, Sandra, and Gary Sandefur. 1994. Growing Up with a Single Parent: What Hurts, What Helps. Harvard University Press: Cambridge, MA.

Meyer, John D., Nicholas Warren, and Susan Reisine. 2007. "Job Controls, Substantive Complexity, and Risk for Low Birth Weight and Preterm Delivery: An Analysis From a State Birth Registry." American Journal of Industrial Medicine 50 (September): 664-75.

Mongelli, Max, and Jason Gardosi. 2000. "Fetal Growth." Current Opinion in Obstetrics and Gynecology 12 (April): 111-115.

NICHD Early Child Care Research Network, and Duncan G. 2003. "Modeling the Impact of Child Care Quality on Children's Cognitive Development." Child Development 74 (October): $1454-75$.

Oster, Emily. 2005. "Hepatitis B and the Case of the Missing Women." Journal of Political Economy 113 (December): 1163-1216.

Penn and Owen. 2002. "Factors Associated with Continued Smoking During Pregnancy: Analysis of Socio-Demographic, Pregnancy and Smoking-Related Factors." Drug and Alcohol Review 21 (March): 17-25.

Plomin, Robert. 1999. "Genetics and General Cognitive Ability." Nature 402 (2 December, supplement): C25-C29.

Reichman, Nancy E., Corman, Hope, Noonan, Kelly and Dave Dhaval. 2006. "Typically Unobserved Variables (TUVs) and Selection into Prenatal Inputs: Implications for Estimating Infant Health Production Functions." NBER Working Paper No. 12004. National Bureau of Economic Research: Cambridge, MA.

Rosenzweig, Mark R. 1986. "Birth Spacing and Sibling Inequality: Asymmetric Information within the Family." International Economic Review 27 (February): 55-76.

Rosenzweig, Mark R., and T. Paul Schultz. 1983. "Estimating a Household Production Function: Heterogeneity, the Demand for Health Inputs, and Their Effects of Birth Weight." Journal of Political Economy 91 (October): 723-46. (a)

Rosenzweig, Mark R., and T. Paul Schultz. 1983. "Consumer Demand and Household Production: The Relationship Between Fertility and Child Mortality." American Economic Review Papers and Proceedings 73 (May): 38-42. (b)

Rosenzweig, Mark R., and Kenneth I. Wolpin. 1988. "Heterogeneity, Intrafamily Distribution and Child Health." Journal of Human Resources 23 (Autumn): 437-61. 
Rosenzweig, Mark R., and Kenneth I. Wolpin. 1991. "Inequality at Birth: The Scope for Policy Intervention." Journal of Econometrics 50 (October): 205-28.

Rosenzweig, Mark R., and Kenneth I. Wolpin. 1994. "Are There Increasing Returns to the Intergenerational Production of Human Capital? Maternal Schooling and Child Intellectual Achievement." Journal of Human Resources 29 (Spring): 670-93.

Rosenzweig, Mark R., and Kenneth I. Wolpin. 1995. "Sisters, Siblings, and Mothers: The Effect of Teen-age Childbearing on Birth Outcomes in a Dynamic Family Context." Econometrica 63 (March): 303-26.

Royer, Heather. 2005. "Does Maternal Age Affect Infant Health?: Evidence from Sibling Comparisons." Manuscript. Ann Arbor: University of Michigan.

Ruhm, Christopher J. 2000. "Parental Leave and Child Health." Journal of Health Economics 19 (November): 931-60.

Ruhm, Christopher J. 2004. "Parental Employment and Child Cognitive Development." Journal of Human Resources 39 (Winter): 155-92.

Sexton, M., and J. R. Hebel. 1984. "A Clinical Trial of Change in Maternal Smoking and Its Effect on Birth Weight." Journal of the American Medical Association 251 (February): 911-15.

Slotkin, Theodore A. 1998. "Fetal Nicotine of Cocaine Exposure: Which One is Worse?." Journal of Pharmacology and Experimental Therapeutics 285 (June): 931-45.

Spong, Catherine Y. 2007. "Prediction and Prevention of Recurrent Spontaneous Preterm Birth." Obstetrics and Gynecology 110 (August): 405-415.

Strobino, Donna M., Margaret E. Ensminger, Young J. Kim, and Joy Nanda. 1995. "Mechanisms for Maternal Age Differences in Birth Weight." American Journal of Epidemiology 142 (September): 504-14.

Tominey, Emma. 2007. "Maternal Smoking During Pregnancy and Early Child Outcomes." CEP Discussion Paper No. 828. London: London School of Economics.

U.S. Department of Health and Human Services. 2000. Healthy People 2010: Understanding and Improving Health. Second edition. Washington, DC: U.S. Government Printing Office.

Valero de Bernabé, Javier, Trinidad Soriano, Romana Albaladejo, Margarita Juarranz, María Elisa Calle, David Martínez, and Vincente Domíniguez-Rojas. 2004. "Risk Factors for Low Birth Weight: A Review." European Journal of Obstetrics and Gynecology and Reproductive Biology 116 (September): 3-15.

Walsh, Raoul A. 1994. "Effects of Maternal Smoking on Adverse Pregnancy Outcomes: Examination of the Criteria of Causation." Human Biology 66 (December): 1059-92.

Yang, Q., S.W. Wen, A. Leader, X.K. Chen, J. Lipson, and M. Walker. 2007. "Paternal Age and Birth Defects: How Strong is the Association?" Human Reproduction 22 (December): 696-701. 
Figure 1: Distribution of Birth Weight and Fetal Growth
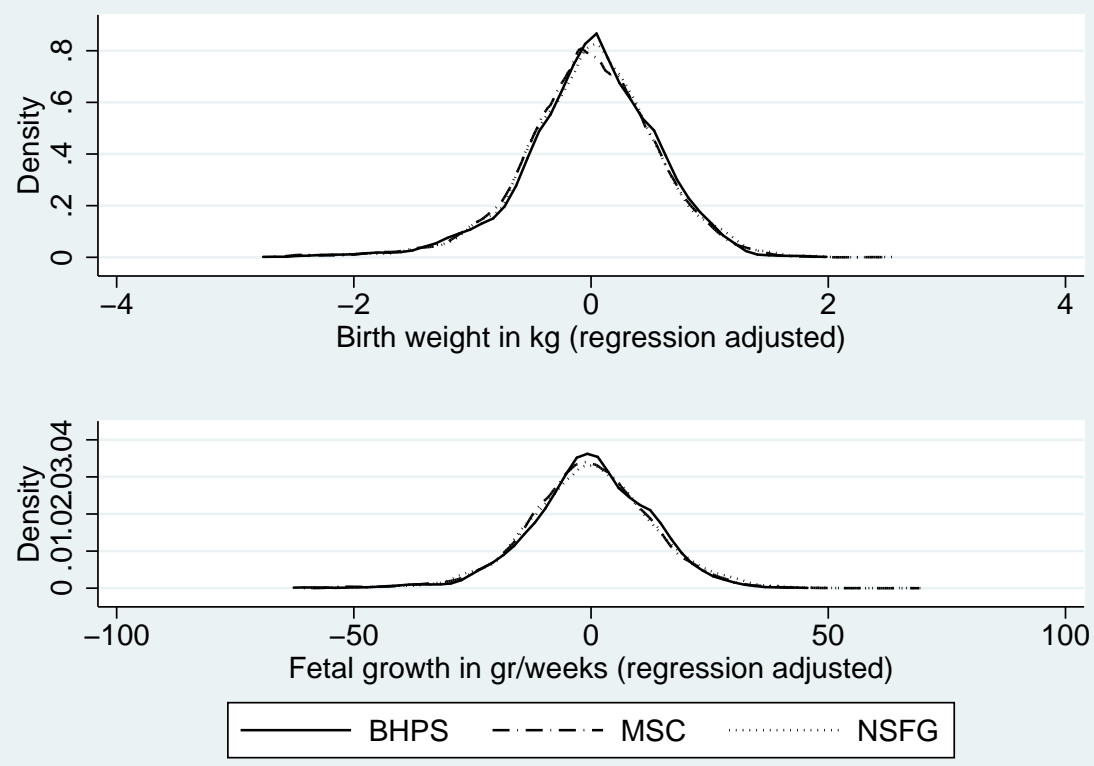

Notes: Kernel density estimates of regression adjusted measures of birth weight (kg) and fetal growth $(\mathrm{g} / \mathrm{wks})$ in the BHPS, MCS and NSFG samples. Data obtained from the residuals of OLS regressions of birth weight or fetal growth on year dummies and quarter of birth dummies.

Figure 2: Average Birth Weight by Gestation

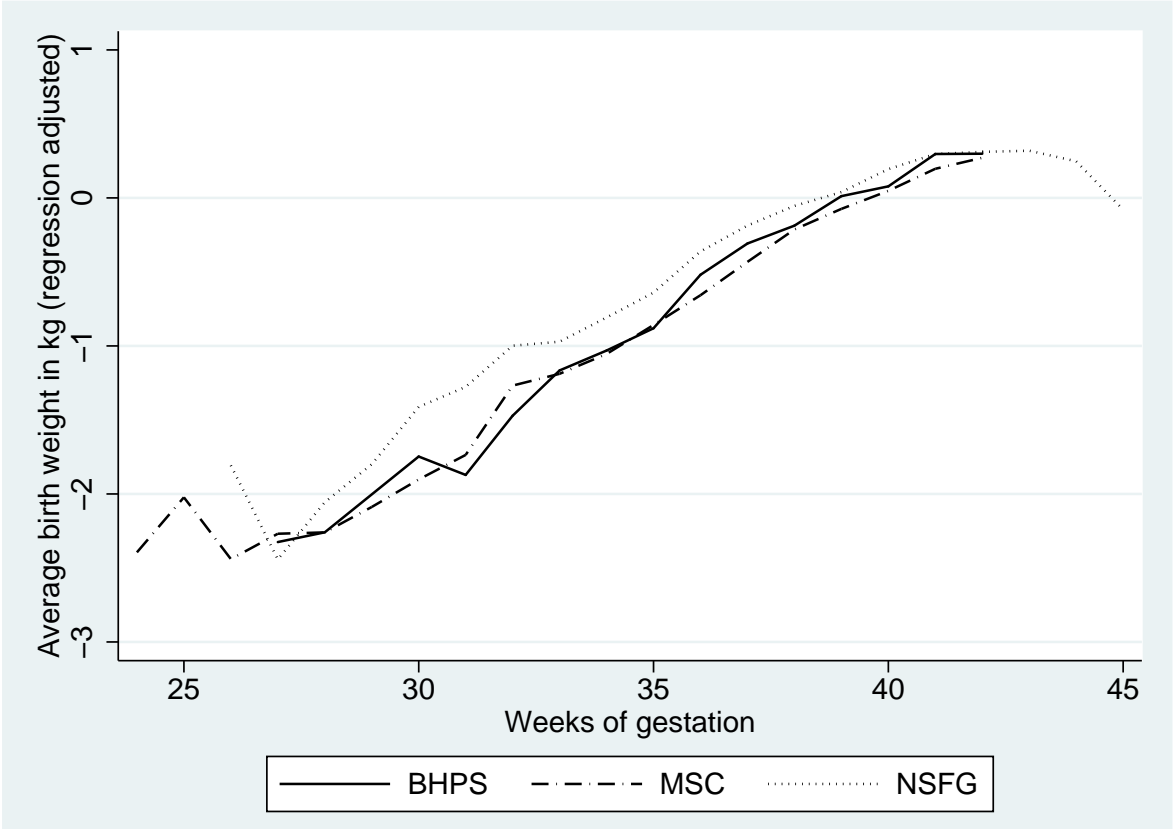

Notes: Average birth weight by week of gestation for singleton births. Data obtained from the residuals of OLS regressions of birth weight on year dummies and quarter of birth dummies. 
Table 1: Descriptive Statistics

\begin{tabular}{|c|c|c|c|}
\hline & BHPS & MCS & NSFG \\
\hline Birth weight (kg) & $\begin{array}{c}3.321 \\
(0.560)\end{array}$ & $\begin{array}{c}3.382 \\
(0.564)\end{array}$ & $\begin{array}{c}3.349 \\
(0.573)\end{array}$ \\
\hline Birth weight (kg, regression adjusted) & $\begin{array}{l}0.000 \\
(0.557)\end{array}$ & $\begin{array}{c}0.000 \\
(0.564)\end{array}$ & $\begin{array}{c}0.000 \\
(0.572)\end{array}$ \\
\hline Fetal growth (g/wks) & $\begin{array}{c}83.731 \\
(12.590)\end{array}$ & $\begin{array}{c}85.107 \\
(12.827)\end{array}$ & $\begin{array}{c}86.082 \\
(13.552)\end{array}$ \\
\hline Fetal growth in (g/wks, regression adjusted) & $\begin{array}{c}0.000 \\
(12.513)\end{array}$ & $\begin{array}{c}0.000 \\
(12.825)\end{array}$ & $\begin{array}{c}0.000 \\
(13.506)\end{array}$ \\
\hline Gestation & $\begin{array}{l}39.549 \\
(2.000)\end{array}$ & $\begin{array}{l}39.641 \\
(1.910)\end{array}$ & $\begin{array}{l}38.832 \\
(1.982)\end{array}$ \\
\hline Low birth weigh (birth weight $<2500 \mathrm{~g}$ ) & 0.07 & 0.06 & 0.07 \\
\hline Mother smoked during pregnancy & 0.225 & 0.259 & 0.127 \\
\hline $\begin{array}{l}\text { Mother stopped working }<1 \text { month before birth } \\
\text { Mother stopped working } 1-2 \text { months before birth } \\
\text { Mother stopped working } 3+\text { months before birth } \\
\text { Mother did not work during pregnancy } \\
\text { Mother did not report information on labor supply }\end{array}$ & $\begin{array}{l}0.158 \\
0.134 \\
0.099 \\
0.397 \\
0.211\end{array}$ & $\begin{array}{l}0.302 \\
0.283 \\
0.086 \\
0.329\end{array}$ & $\begin{array}{l}0.244 \\
0.078 \\
0.044 \\
0.502 \\
0.131\end{array}$ \\
\hline $\begin{array}{l}\text { Child sex (male) } \\
\text { First born child } \\
\text { Mother's age at birth of the child (years) }\end{array}$ & $\begin{array}{l}0.495 \\
0.681 \\
28.013 \\
(5.751)\end{array}$ & $\begin{array}{l}0.514 \\
0.416 \\
29.272 \\
(5.794)\end{array}$ & $\begin{array}{l}0.505 \\
0.523 \\
24.675 \\
(5.513)\end{array}$ \\
\hline $\begin{array}{l}\text { Mother never drank alcohol during pregnancy } \\
\text { Mother drank alcohol every day during pregnancy } \\
\text { Received antenatal care in the first trimester } \\
\text { Body mass index (before pregnancy) }{ }^{a}\end{array}$ & & $\begin{array}{c}0.711 \\
0.006 \\
0.844 \\
23.729 \\
(4.426)\end{array}$ & \\
\hline $\begin{array}{l}\text { Father smoked during pregnancy } \\
\text { No father present during pregnancy } \\
\text { Information on father missing }\end{array}$ & $\begin{array}{l}0.233 \\
0.131 \\
0.113\end{array}$ & $\begin{array}{l}0.288 \\
0.142\end{array}$ & \\
\hline $\begin{array}{l}\text { Breastfeeding initiation } \\
\text { Breastfeeding duration (weeks) }{ }^{b}\end{array}$ & & & $\begin{array}{c}0.483 \\
25.285 \\
(26.851)\end{array}$ \\
\hline $\begin{array}{l}\text { Number of observations } \\
\text { Number of mothers } \\
\text { Number of siblings-pairs } \\
\text { Number of siblings-triplets }\end{array}$ & $\begin{array}{c}1,339 \\
912 \\
327 \\
50\end{array}$ & $\begin{array}{l}17,483 \\
17,483\end{array}$ & $\begin{array}{l}12,166 \\
6,153 \\
2,417 \\
1,798\end{array}$ \\
\hline
\end{tabular}

Notes: Variable means (standard deviations of continuous variables are in parentheses).

${ }^{a}$ Mean and standard deviation calculated on 16,425 non-missing observations only.

${ }^{b}$ Includes censored spells. 
Table 2: OLS and FE Estimates of Maternal Smoking and Maternal Labor Supply on Birth Outcomes, by Sample

\begin{tabular}{|c|c|c|c|c|}
\hline & \multicolumn{2}{|c|}{$\begin{array}{c}\text { Birth weight } \\
(\mathrm{kg})\end{array}$} & \multicolumn{2}{|c|}{$\begin{array}{l}\text { Fetal growth } \\
\text { (g/wks) }\end{array}$} \\
\hline & OLS & $\mathrm{FE}$ & OLS & FE \\
\hline & (i) & (ii) & (i) & (ii) \\
\hline & \multicolumn{4}{|c|}{$\mathbf{B H P S}^{a}$} \\
\hline Mother smoked during pregnancy & $\begin{array}{c}-0.187^{* *} \\
(0.043)\end{array}$ & $\begin{array}{c}-0.189^{*} \\
(0.095)\end{array}$ & $\begin{array}{c}-4.143^{* *} \\
(0.954)\end{array}$ & $\begin{array}{l}-4.687^{*} \\
(2.059)\end{array}$ \\
\hline Mother stopped working 1-2 months before birth & $\begin{array}{c}0.168^{* *} \\
(0.060)\end{array}$ & $\begin{array}{l}0.187^{*} \\
(0.075)\end{array}$ & $\begin{array}{l}2.948^{*} \\
(1.355)\end{array}$ & $\begin{array}{l}3.730^{*} \\
(1.632)\end{array}$ \\
\hline Mother stopped working $3+$ months before birth & $\begin{array}{c}0.169^{* *} \\
(0.064)\end{array}$ & $\begin{array}{c}0.241^{* *} \\
(0.079)\end{array}$ & $\begin{array}{l}3.238^{*} \\
(1.431)\end{array}$ & $\begin{array}{l}4.257^{*} \\
(1.710)\end{array}$ \\
\hline Mother did not work during pregnancy & $\begin{array}{l}0.110^{*} \\
(0.047)\end{array}$ & $\begin{array}{l}0.143^{*} \\
(0.062)\end{array}$ & $\begin{array}{c}1.995 \\
(1.046)\end{array}$ & $\begin{array}{l}2.645 \\
(1.354)\end{array}$ \\
\hline & \multicolumn{4}{|c|}{$\mathbf{M C S}^{b}$} \\
\hline Mother smoked during pregnancy & $\begin{array}{c}-0.203^{* *} \\
(0.013)\end{array}$ & & $\begin{array}{c}-4.787^{* *} \\
(0.293)\end{array}$ & \\
\hline Mother stopped working 1-2 months before birth & $\begin{array}{c}0.161^{* *} \\
(0.012)\end{array}$ & & $\begin{array}{c}2.661^{* *} \\
(0.297)\end{array}$ & \\
\hline Mother stopped working $3+$ months before birth & $\begin{array}{r}0.086^{* *} \\
(0.021)\end{array}$ & & $\begin{array}{l}1.565^{* *} \\
(0.461)\end{array}$ & \\
\hline Mother did not work during pregnancy & $\begin{array}{r}0.069^{* *} \\
(0.016)\end{array}$ & & $\begin{array}{r}1.078^{* *} \\
(0.352)\end{array}$ & \\
\hline & \multicolumn{4}{|c|}{$\mathbf{N S F G}^{c}$} \\
\hline Mother smoked during pregnancy & $\begin{array}{c}-0.139^{* *} \\
(0.017)\end{array}$ & $\begin{array}{c}-0.140^{* *} \\
(0.044)\end{array}$ & $\begin{array}{c}-3.588^{* *} \\
(0.390)\end{array}$ & $\begin{array}{c}-3.523^{* *} \\
(1.032)\end{array}$ \\
\hline Mother stopped working 1-2 months before birth & $\begin{array}{c}0.067^{* *} \\
(0.021)\end{array}$ & $\begin{array}{l}0.063^{*} \\
(0.027)\end{array}$ & $\begin{array}{l}1.084^{*} \\
(0.506)\end{array}$ & $\begin{array}{c}0.701 \\
(0.635)\end{array}$ \\
\hline Mother stopped working $3+$ months before birth & $\begin{array}{c}0.023 \\
(0.026)\end{array}$ & $\begin{array}{c}0.061 \\
(0.034)\end{array}$ & $\begin{array}{c}0.238 \\
(0.611)\end{array}$ & $\begin{array}{c}0.678 \\
(0.799)\end{array}$ \\
\hline Mother did not work during pregnancy & $\begin{array}{c}0.021 \\
(0.015)\end{array}$ & $\begin{array}{l}0.043^{*} \\
(0.020)\end{array}$ & $\begin{array}{c}0.222 \\
(0.345)\end{array}$ & $\begin{array}{c}0.670 \\
(0.480)\end{array}$ \\
\hline
\end{tabular}

Notes: The dependent variable is the residual from an OLS regression of birth weight or fetal growth on time and quarter of birth dummies. Estimates are obtained from OLS or FE sibling models. Standard errors in parentheses.

${ }^{a}$ BHPS: Base category for maternal labor supply is mothers who stopped working less than a month before birth; an additional variable indicating that the mother never stopped working or did not report information on maternity leave is included but not shown. All specifications include maternal age and its square, and dummies for firstborn child, child sex, mother's ethnicity and highest educational qualification. OLS standard errors are adjusted for clustering at the mother's level. Number of births is 1,339 , and number of mothers is 912 .

${ }^{b}$ MCS: Base category for maternal labor supply is mothers who stopped working less than a month before birth. All specifications include maternal age and its square, and dummies for firstborn child, child sex, mother's ethnicity and highest educational qualification. Number of births (and mothers) is 17,483 .

${ }^{c}$ NSFG: Base category for maternal labor supply is mothers who stopped working less than a month before birth; an additional variable indicating that the mother never stopped working or did not report information on maternity leave is included but not shown. All specifications include maternal age at birth and its square, and dummies for firstborn child, child sex, mother's ethnicity and highest educational qualification. OLS standard errors are adjusted for clustering at the mother's level. Number of births is 12,166 , and number of mothers is 6,153 .

** Statistically significant at the 0.01 level, * statistically significant at the 0.05 level. 
Table 3: GMM Estimates of Maternal Smoking and Maternal Labor Supply on Birth Outcomes Two- and Three-Child Families, NSFG

\begin{tabular}{|c|c|c|c|c|}
\hline & \multicolumn{2}{|c|}{$\begin{array}{c}\text { Birth weight } \\
(\mathrm{kg})\end{array}$} & \multicolumn{2}{|c|}{$\begin{array}{l}\text { Fetal growth } \\
\text { (g/wks) }\end{array}$} \\
\hline & FE-IV & FE-IV & FE-IV & FE-IV \\
\hline & (i) & (ii) & (i) & (ii) \\
\hline Mother smoked during pregnancy & $\begin{array}{c}-0.151^{* *} \\
(0.036)\end{array}$ & $\begin{array}{c}-0.164^{* *} \\
(0.042)\end{array}$ & $\begin{array}{r}-3.557^{*} \\
(1.421)\end{array}$ & $\begin{array}{l}-3.618^{*} \\
(1.279)\end{array}$ \\
\hline Mother stopped working 1-2 months before birth & $\begin{array}{c}0.092^{* *} \\
(0.034)\end{array}$ & $\begin{array}{c}0.096^{* *} \\
(0.029)\end{array}$ & $\begin{array}{l}0.894^{*} \\
(0.388)\end{array}$ & $\begin{array}{l}0.883^{*} \\
(0.356)\end{array}$ \\
\hline Mother stopped working $3+$ months before birth & $\begin{array}{c}0.071 \\
(0.064)\end{array}$ & $\begin{array}{c}0.070 \\
(0.056)\end{array}$ & $\begin{array}{c}0.514 \\
(0.821)\end{array}$ & $\begin{array}{c}0.525 \\
(0.826)\end{array}$ \\
\hline Mother did not work during pregnancy & $\begin{array}{l}0.046 \\
(0.025)\end{array}$ & $\begin{array}{l}0.048^{*} \\
(0.021)\end{array}$ & $\begin{array}{l}0.547 \\
(0.469)\end{array}$ & $\begin{array}{l}0.648 \\
(0.612)\end{array}$ \\
\hline Covariance between family fixed effects $(\mu)$ and: & & & & \\
\hline Mother smoked during first pregnancy & $\begin{array}{l}-0.038^{*} \\
(0.016)\end{array}$ & $\begin{array}{c}-0.039^{* *} \\
(0.014)\end{array}$ & $\begin{array}{l}-0.210^{*} \\
(0.087)\end{array}$ & $\begin{array}{l}-0.622^{*} \\
(0.287)\end{array}$ \\
\hline Mother smoked during second pregnancy & $\begin{array}{c}0.010 \\
(0.047)\end{array}$ & & $\begin{array}{l}-0.148 \\
(0.155)\end{array}$ & \\
\hline Mother smoked during third pregnancy & $\begin{array}{l}-0.006 \\
(0.011)\end{array}$ & & $\begin{array}{l}-0.36 \\
(0.162)\end{array}$ & \\
\hline Mother stopped working 1-2 months before first birth & $\begin{array}{c}0.011^{* *} \\
(0.004)\end{array}$ & $\begin{array}{c}0.012^{* *} \\
(0.004)\end{array}$ & $\begin{array}{r}0.139^{* *} \\
(0.044)\end{array}$ & $\begin{array}{r}0.151^{* *} \\
(0.046)\end{array}$ \\
\hline Mother stopped working 1-2 months before second birth & $\begin{array}{c}0.003 \\
(0.016)\end{array}$ & & $\begin{array}{l}-0.114^{*} \\
(0.051)\end{array}$ & $\begin{array}{l}-0.107^{*} \\
(0.042)\end{array}$ \\
\hline Mother stopped working 1-2 months before third birth & $\begin{array}{l}0.020^{*} \\
(0.009)\end{array}$ & $\begin{array}{l}0.024^{*} \\
(0.010)\end{array}$ & $\begin{array}{r}0.156^{* *} \\
(0.039)\end{array}$ & $\begin{array}{r}0.164^{* *} \\
(0.035)\end{array}$ \\
\hline Mother stopped working $3+$ months before first birth & $\begin{array}{c}0.002 \\
(0.007)\end{array}$ & & $\begin{array}{l}0.125^{*} \\
(0.057)\end{array}$ & $\begin{array}{r}0.127^{* *} \\
(0.040)\end{array}$ \\
\hline Mother stopped working $3+$ months before second birth & $\begin{array}{l}-0.001 \\
(0.010)\end{array}$ & & $\begin{array}{c}0.062 \\
(0.194)\end{array}$ & \\
\hline Mother stopped working $3+$ months before third birth & $\begin{array}{l}-0.003 \\
(0.026)\end{array}$ & & $\begin{array}{l}-0.077 \\
(0.184)\end{array}$ & \\
\hline Mother did not work during first pregnancy & $\begin{array}{l}-0.008^{*} \\
(0.004)\end{array}$ & $\begin{array}{l}-0.009^{*} \\
(0.004)\end{array}$ & $\begin{array}{l}-0.021 \\
(0.056)\end{array}$ & \\
\hline Mother did not work during second pregnancy & $\begin{array}{l}-0.005 \\
(0.018)\end{array}$ & & $\begin{array}{l}-0.018 \\
(0.092)\end{array}$ & \\
\hline Mother did not work during third pregnancy & $\begin{array}{c}0.005 \\
(0.0016)\end{array}$ & & $\begin{array}{l}0.048^{*} \\
(0.022)\end{array}$ & $\begin{array}{l}0.049^{*} \\
(0.020)\end{array}$ \\
\hline Covariance between first child endowment $\left(\phi_{1}\right)$ and: & & & & \\
\hline Mother smoked during second pregnancy & $\begin{array}{c}-0.043^{* *} \\
(0.015)\end{array}$ & $\begin{array}{c}-0.045^{* *} \\
(0.016)\end{array}$ & $\begin{array}{c}-0.061^{*} \\
(0.024)\end{array}$ & $\begin{array}{c}-0.073^{* *} \\
(0.020)\end{array}$ \\
\hline Mother smoked during third pregnancy & $\begin{array}{c}-0.019^{*} \\
(0.009)\end{array}$ & $\begin{array}{c}-0.022^{*} \\
(0.009)\end{array}$ & $\begin{array}{c}-0.028^{*} \\
(0.012)\end{array}$ & $\begin{array}{c}-0.026^{* *} \\
(0.010)\end{array}$ \\
\hline Mother stopped working 1-2 months before second birth & $\begin{array}{l}0.026^{*} \\
(0.012)\end{array}$ & $\begin{array}{l}0.029^{*} \\
(0.012)\end{array}$ & $\begin{array}{c}0.008 \\
(0.062)\end{array}$ & \\
\hline Mother stopped working 1-2 months before third birth & $\begin{array}{l}-0.006 \\
(0.018)\end{array}$ & & $\begin{array}{l}-0.011 \\
(0.079)\end{array}$ & \\
\hline Mother stopped working $3+$ months before second birth & $\begin{array}{l}0.008^{*} \\
(0.003)\end{array}$ & $\begin{array}{l}0.008^{*} \\
(0.003)\end{array}$ & $\begin{array}{l}0.097^{*} \\
(0.044)\end{array}$ & $\begin{array}{l}0.102^{*} \\
(0.039)\end{array}$ \\
\hline Mother stopped working $3+$ months before third birth & $\begin{array}{l}-0.002 \\
(0.011)\end{array}$ & & $\begin{array}{l}0.088^{*} \\
(0.040)\end{array}$ & $\begin{array}{r}0.087^{* *} \\
(0.031)\end{array}$ \\
\hline Mother did not work during second pregnancy & $\begin{array}{c}0.021 \\
(0.035)\end{array}$ & & $\begin{array}{l}0.152^{*} \\
(0.071)\end{array}$ & $\begin{array}{l}0.156^{*} \\
(0.064)\end{array}$ \\
\hline
\end{tabular}


Table 3: (continued)

\begin{tabular}{|c|c|c|c|c|}
\hline Mother did not work during third pregnancy & $\begin{array}{c}0.016 \\
(0.028)\end{array}$ & & $\begin{array}{l}0.120^{*} \\
(0.054)\end{array}$ & $\begin{array}{l}0.123^{*} \\
(0.042)\end{array}$ \\
\hline \multicolumn{5}{|l|}{ Covariance between second child endowment $\left(\phi_{2}\right)$ and: } \\
\hline Mother smoked during third pregnancy & $\begin{array}{l}-0.011 \\
(0.013)\end{array}$ & & $\begin{array}{l}-0.009 \\
(0.024)\end{array}$ & \\
\hline Mother stopped working 1-2 months before third birth & $\begin{array}{c}0.025^{* *} \\
(0.008)\end{array}$ & $\begin{array}{c}0.024^{* *} \\
(0.007)\end{array}$ & $\begin{array}{l}0.037^{*} \\
(0.015)\end{array}$ & $\begin{array}{l}0.041^{*} \\
(0.016)\end{array}$ \\
\hline Mother stopped working $3+$ months before third birth & $\begin{array}{c}0.011 \\
(0.012)\end{array}$ & & $\begin{array}{c}0.027 \\
(0.034)\end{array}$ & \\
\hline Mother did not work during third pregnancy & $\begin{array}{c}0.007 \\
(0.014)\end{array}$ & & $\begin{array}{c}0.074 \\
(0.116)\end{array}$ & \\
\hline \multicolumn{5}{|l|}{ Endowment variances } \\
\hline$\sigma_{\mu}^{2}$ & $\begin{array}{l}0.164^{*} \\
(0.078)\end{array}$ & $\begin{array}{c}0.171^{* *} \\
(0.067)\end{array}$ & $\begin{array}{l}3.908^{*} \\
(1.457)\end{array}$ & $\begin{array}{l}4.116^{* *} \\
(1.338)\end{array}$ \\
\hline$\sigma_{\phi_{1}}^{2}$ & $\begin{array}{c}0.372 \\
(0.233)\end{array}$ & $\begin{array}{c}0.360 \\
(0.218)\end{array}$ & $\begin{array}{l}4.015^{*} \\
(1.978)\end{array}$ & $\begin{array}{l}3.951^{*} \\
(1.764)\end{array}$ \\
\hline$\sigma_{\phi_{2}}^{2}$ & $\begin{array}{c}0.410 \\
(0.387)\end{array}$ & $\begin{array}{c}0.397 \\
(0.326)\end{array}$ & $\begin{array}{l}2.945^{*} \\
(1.338)\end{array}$ & $\begin{array}{c}3.024^{* *} \\
(1.245)\end{array}$ \\
\hline$\sigma_{\phi_{3}}^{2}$ & $\begin{array}{l}0.579^{*} \\
(0.242)\end{array}$ & $\begin{array}{c}0.551^{* *} \\
(0.236)\end{array}$ & $\begin{array}{l}3.242^{*} \\
(1.466)\end{array}$ & $\begin{array}{l}3.103^{*} \\
(1.528)\end{array}$ \\
\hline \multicolumn{5}{|l|}{ Goodness of Fit Tests ${ }^{a}$} \\
\hline FE-IV model vs. & & & & \\
\hline FE model & $39.1(25)^{*}$ & $19.4(9)^{*}$ & $41.4(25)^{*}$ & $22.6(11)^{*}$ \\
\hline OLS & $79.3(51)^{* *}$ & $37.8(16)^{* *}$ & $79.8(51)^{* *}$ & $39.4(19)^{* *}$ \\
\hline $\begin{array}{l}\text { FE model vs. } \\
\text { OLS }\end{array}$ & $38.2(26)^{*}$ & $21.1(7)^{* *}$ & $39.0(26)^{*}$ & $23.2(8)^{* *}$ \\
\hline Overidentifying restriction test ${ }^{b}$ & $0.235(28)$ & $0.171(49)$ & $0.242(28)$ & $0.193(48)$ \\
\hline
\end{tabular}

Notes: Estimates are obtained from the FE-IV model estimated using GMM techniques on specifications that include maternal smoking, maternal labor supply (including a dummy variable indicating that the mother did not report information on maternity leave), maternal age at birth and its square, and dummy variables for first born and child sex. Standard errors are in parentheses. Column (ii) reports a restricted specification in which the endowment covariance components that are statistically insignificant in column (i) are set to zero (including also those parameters not reported in the table). The overidentifying restriction test shown at the bottom of the table takes account of such restrictions and other restrictions discussed in the text. Number of births is 10,228 , and number of mothers is 4,215 .

${ }^{a}$ Figures in this panel are $\chi^{2}$ (d.f.) statistics. Both OLS and FE models are nested in the FE-IV model. For comparability, therefore, OLS estimates are obtained from variants of the models presented in Table 2, from which mother's ethnicity and highest educational qualification are excluded. The last raw reports the $p$-value of the joint significance test on the restrictions imposed by specification (ii) with respect to specification (i).

${ }_{b}^{b}$ This row reports the $p$-value of the overidentifying restriction test (d.f.) for each specification.

$* *$ Statistically significant at the 0.01 level, * statistically significant at the 0.05 level. 
Table 4: GMM Estimates of Maternal Smoking and Maternal Labor Supply on Birth Outcomes Two-Child Families Only, BHPS

\begin{tabular}{|c|c|c|c|c|}
\hline & \multicolumn{2}{|c|}{$\begin{array}{l}\text { Birth weight } \\
(\mathrm{kg})\end{array}$} & \multicolumn{2}{|c|}{$\begin{array}{l}\text { Fetal growth } \\
(\mathrm{g} / \mathrm{wks})\end{array}$} \\
\hline & FE-IV & FE-IV & FE-IV & FE-IV \\
\hline & (i) & (ii) & (i) & (ii) \\
\hline Mother smoked during pregnancy $(s)$ & $\begin{array}{l}-0.189 \\
(0.293)\end{array}$ & $\begin{array}{l}-0.191 \\
(0.107)\end{array}$ & $\begin{array}{l}-4.281^{*} \\
(2.165)\end{array}$ & $\begin{array}{l}-4.319^{*} \\
(2.087)\end{array}$ \\
\hline Mother stopped working 1-2 months before birth $\left(m^{1}\right)$ & $\begin{array}{c}0.170 \\
(0.114)\end{array}$ & $\begin{array}{c}0.178 \\
(0.092)\end{array}$ & $\begin{array}{c}3.698 \\
(1.969)\end{array}$ & $\begin{array}{l}3.726^{*} \\
(1.841)\end{array}$ \\
\hline Mother stopped working $3+$ months before birth $\left(m^{2}\right)$ & $\begin{array}{l}0.250^{*} \\
(0.100)\end{array}$ & $\begin{array}{r}0.247^{* *} \\
(0.089)\end{array}$ & $\begin{array}{l}4.232^{* *} \\
(1.593)\end{array}$ & $\begin{array}{l}4.208^{* *} \\
(1.570)\end{array}$ \\
\hline Mother did not work during pregnancy $\left(m^{3}\right)$ & $\begin{array}{l}0.136 \\
(0.092)\end{array}$ & $\begin{array}{c}0.140 \\
(0.074)\end{array}$ & $\begin{array}{c}2.269 \\
(1.933)\end{array}$ & $\begin{array}{c}2.316 \\
(1.824)\end{array}$ \\
\hline $\begin{array}{l}\text { Covariance between family fixed effects }(\mu) \text { and: } \\
\text { Mother smoked during first pregnancy }\end{array}$ & $\begin{array}{c}-0.049^{*} \\
(0.022)\end{array}$ & $\begin{aligned}-0.055^{*} \\
(0.020)\end{aligned}$ & $\begin{array}{l}-0.108 \\
(0.063)\end{array}$ & \\
\hline Mother smoked during second pregnancy & $\begin{array}{l}-0.091^{*} \\
(0.044)\end{array}$ & $\begin{array}{c}-0.087^{*} \\
(0.041)\end{array}$ & $\begin{array}{c}-0.326^{*} \\
(0.166)\end{array}$ & $\begin{array}{l}-0.358^{*} \\
(0.152)\end{array}$ \\
\hline Mother stopped working 1-2 months before first birth & $\begin{array}{l}-0.006 \\
(0.013)\end{array}$ & & $\begin{array}{l}-0.157 \\
(0.278)\end{array}$ & \\
\hline Mother stopped working 1-2 months before second birth & $\begin{array}{l}-0.003 \\
(0.013)\end{array}$ & & $\begin{array}{l}-0.08 \\
(0.245)\end{array}$ & \\
\hline Mother stopped working $3+$ months before first birth & $\begin{array}{l}0.018 \\
(0.02)\end{array}$ & & $\begin{array}{c}0.377 \\
(0.352)\end{array}$ & \\
\hline Mother stopped working $3+$ months before second birth & $\begin{array}{l}-0.022 \\
(0.014)\end{array}$ & & $\begin{array}{c}-0.248 \\
(0.291)\end{array}$ & \\
\hline Mother did not work during first pregnancy & $\begin{array}{c}-0.008 \\
(0.019)\end{array}$ & & $\begin{array}{c}-0.189 \\
(0.417)\end{array}$ & \\
\hline Mother did not work during second pregnancy & $\begin{array}{c}0.037 \\
(0.058)\end{array}$ & & $\begin{array}{c}0.219 \\
(0.791)\end{array}$ & \\
\hline Covariance between first child endowment $\left(\phi_{1}\right)$ and: & & & & \\
\hline Mother smoked during second pregnancy & $\begin{array}{c}-0.029^{*} \\
(0.013)\end{array}$ & $\begin{array}{c}-0.027^{*} \\
(0.012)\end{array}$ & $\begin{array}{c}-0.195^{*} \\
(0.091)\end{array}$ & $\begin{array}{c}-0.184^{*} \\
(0.073)\end{array}$ \\
\hline Mother stopped working 1-2 months before second birth & $\begin{array}{l}-0.002 \\
(0.011)\end{array}$ & & $\begin{array}{c}0.093 \\
(0.222)\end{array}$ & \\
\hline Mother stopped working $3+$ months before second birth & $\begin{array}{l}0.032^{*} \\
(0.013)\end{array}$ & $\begin{array}{c}0.033^{* *} \\
(0.012)\end{array}$ & $\begin{array}{c}0.489 \\
(0.296)\end{array}$ & \\
\hline Mother did not work during second pregnancy & $\begin{array}{c}0.021 \\
(0.012)\end{array}$ & & $\begin{array}{c}0.141^{*} \\
(0.066)\end{array}$ & $\begin{array}{l}0.133^{*} \\
(0.059)\end{array}$ \\
\hline $\begin{array}{l}\text { Endowment variances } \\
\sigma_{\mu}^{2}\end{array}$ & $\begin{array}{c}0.325 \\
(2.505)\end{array}$ & $\begin{array}{c}0.366 \\
(1.604)\end{array}$ & $\begin{array}{c}2.892 \\
(3.107)\end{array}$ & $\begin{array}{c}2.791 \\
(2.209)\end{array}$ \\
\hline$\sigma_{\phi_{1}}^{2}$ & $\begin{array}{c}0.391 \\
(0.364)\end{array}$ & $\begin{array}{c}0.413 \\
(0.335)\end{array}$ & $\begin{array}{c}3.789 \\
(2.499)\end{array}$ & $\begin{array}{c}3.802 \\
(2.215)\end{array}$ \\
\hline$\sigma_{\phi_{2}}^{2}$ & $\begin{array}{c}0.132 \\
(0.106)\end{array}$ & $\begin{array}{c}0.187 \\
(0.098)\end{array}$ & $\begin{array}{c}5.063 \\
(3.296)\end{array}$ & $\begin{array}{c}5.106 \\
(3.015)\end{array}$ \\
\hline
\end{tabular}

(continues on next page) 
Table 4: (continued)

\section{Goodness of Fit Tests ${ }^{a}$}

FE-IV model vs.

FE model

OLS

FE model vs.

OLS
$14.3(6)^{*}$

$42.2(19)^{* *}$

$30.4(13)^{* *}$
$11.5(3)^{* *}$

$35.5(8)^{* *}$

$18.0(5)^{* *}$

$0.109(8)$
$12.1(6)$

$44.3(19)^{* *}$

$32.7(13)^{* *}$
$10.2(3)^{*}$

$37.1(7)^{* *}$

$15.6(4)^{* *}$

$0.116(9)$

Overidentifying restriction test ${ }^{b}$

Notes: Estimates are obtained from the FE-IV model estimated using GMM techniques. Standard errors are in parentheses. For definitions and other explanatory variables, see notes to Table 3. Number of births is 654, and number of mothers is 327 .

${ }^{a}$ Figures in this panel are $\chi^{2}$ (d.f.) statistics. For other definitions, see notes to Table 3.

${ }^{b}$ This row reports the p-value (d.f.) of the zero restrictions placed on the insignificant parameters in column (i).

** Statistically significant at the 0.01 level, * statistically significant at the 0.05 level. 
Table 5: Input Heterogeneity Along Mother's Education and Mother's Age at First Birth, BHPS (Two-Child Families Only) and NSFG (Two- and Three-Child Families)

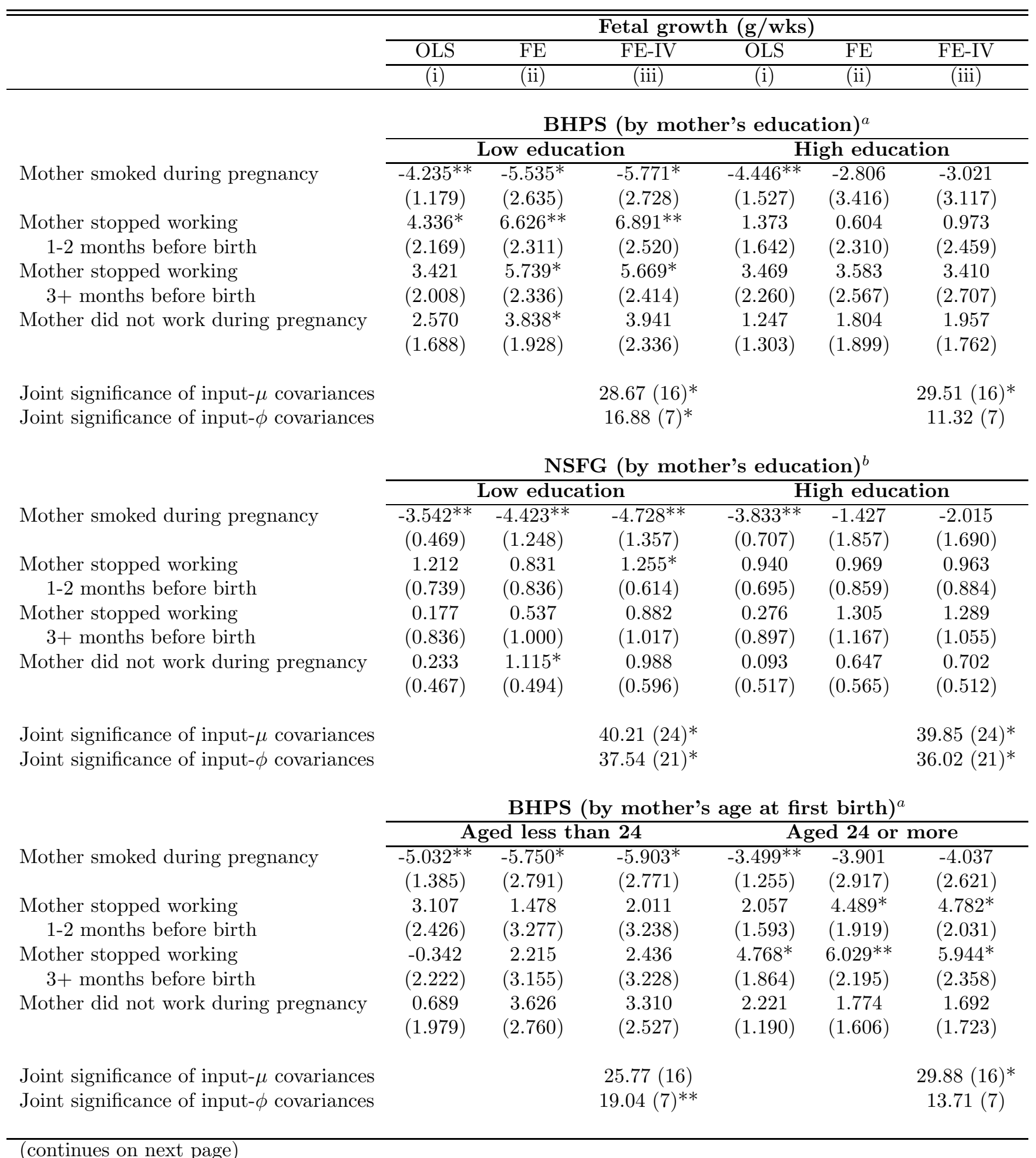


Table 5: (continued)

\begin{tabular}{|c|c|c|c|c|c|c|}
\hline \multirow[b]{3}{*}{ Mother smoked during pregnancy } & \multicolumn{6}{|c|}{ NSFG (by mother's age at first birth) ${ }^{b}$} \\
\hline & \multicolumn{3}{|c|}{ Aged less than 24 } & \multicolumn{3}{|c|}{ Aged 24 or more } \\
\hline & $\begin{array}{c}-2.901^{* *} \\
(0.491)\end{array}$ & $\begin{array}{c}-3.672^{* *} \\
(1.197)\end{array}$ & $\begin{array}{c}-3.884^{* *} \\
(1.281)\end{array}$ & $\begin{array}{c}-4.829^{* *} \\
(0.636)\end{array}$ & $\begin{array}{l}-2.771 \\
(2.104)\end{array}$ & $\begin{array}{c}-3.216 \\
(1.993)\end{array}$ \\
\hline $\begin{array}{l}\text { Mother stopped working } \\
1-2 \text { months before birth }\end{array}$ & $\begin{array}{l}1.696^{*} \\
(0.785)\end{array}$ & $\begin{array}{c}1.071 \\
(0.852)\end{array}$ & $\begin{array}{l}1.283 \\
(0.839)\end{array}$ & $\begin{array}{c}0.790 \\
(0.665)\end{array}$ & $\begin{array}{c}0.758 \\
(0.837)\end{array}$ & $\begin{array}{c}0.954 \\
(0.821)\end{array}$ \\
\hline Mother stopped working & 0.815 & 0.317 & 0.672 & -0.215 & 1.472 & 1.843 \\
\hline $3+$ months before birth & $(0.877)$ & (1.009) & $(1.214)$ & $(0.846)$ & $(1.148)$ & (1.321) \\
\hline Mother did not work during pregnancy & $\begin{array}{c}0.772 \\
(0.474)\end{array}$ & $\begin{array}{c}0.788 \\
(0.466)\end{array}$ & $\begin{array}{c}0.812 \\
(0.684)\end{array}$ & $\begin{array}{l}-0.448 \\
(0.522)\end{array}$ & $\begin{array}{c}1.017 \\
(0.625)\end{array}$ & $\begin{array}{c}0.904 \\
(0.713)\end{array}$ \\
\hline Joint significance of input- $\mu$ covariances & & & $43.18(24)^{* *}$ & & & $34.88(24)$ \\
\hline Joint significance of input- $\phi$ covariances & & & $34.15(21)^{*}$ & & & $36.18(21)^{*}$ \\
\hline
\end{tabular}

Notes: Standard errors are in parentheses. OLS standard errors are adjusted for clustering at the mother's level. For FE-IV models we report the $\chi^{2}$ (d.f.) statistics of the joint significance of the input- $\mu$ and input- $\phi$ covariances.

${ }^{a}$ BHPS: Mothers with low education are all those with O-level (or equivalent) qualifications or below, while mothers with high education are mothers with A-level qualifications or above. Number of births to low education mothers is 717 , and number of mothers is 485 . Number of births to high education mothers is 622 , and number of mothers is 427 . Number of births to mothers aged less than 24 is 385, and number of mothers is 263 . Number of births to mothers aged 24 or more is 954, and number of mothers is 649. For definitions and other explanatory variables, see notes to Tables 2 and 4 .

${ }^{b}$ NSFG: Mothers with low education are all those with high school qualifications or below, while mothers with high education are mothers with some college qualifications or above. Number of births to low education mothers is 7,520 , and number of mothers is 3,651 . Number of births to high education mothers is 4,646 , and number of mothers is 2,502. Number of births to mothers aged less than 24 is 7,543, and number of mothers is 3,511. Number of births to mothers aged 24 or more is 4,632, and number of mothers is 2,642. For definitions and other explanatory variables, see notes to Tables 2 and 3.

** Statistically significant at the 0.01 level, * statistically significant at the 0.05 level. 
Table 6: Father's Smoking as an Instrumental Variable: FE-IV Estimates — Two-Child Families Only, BHPS

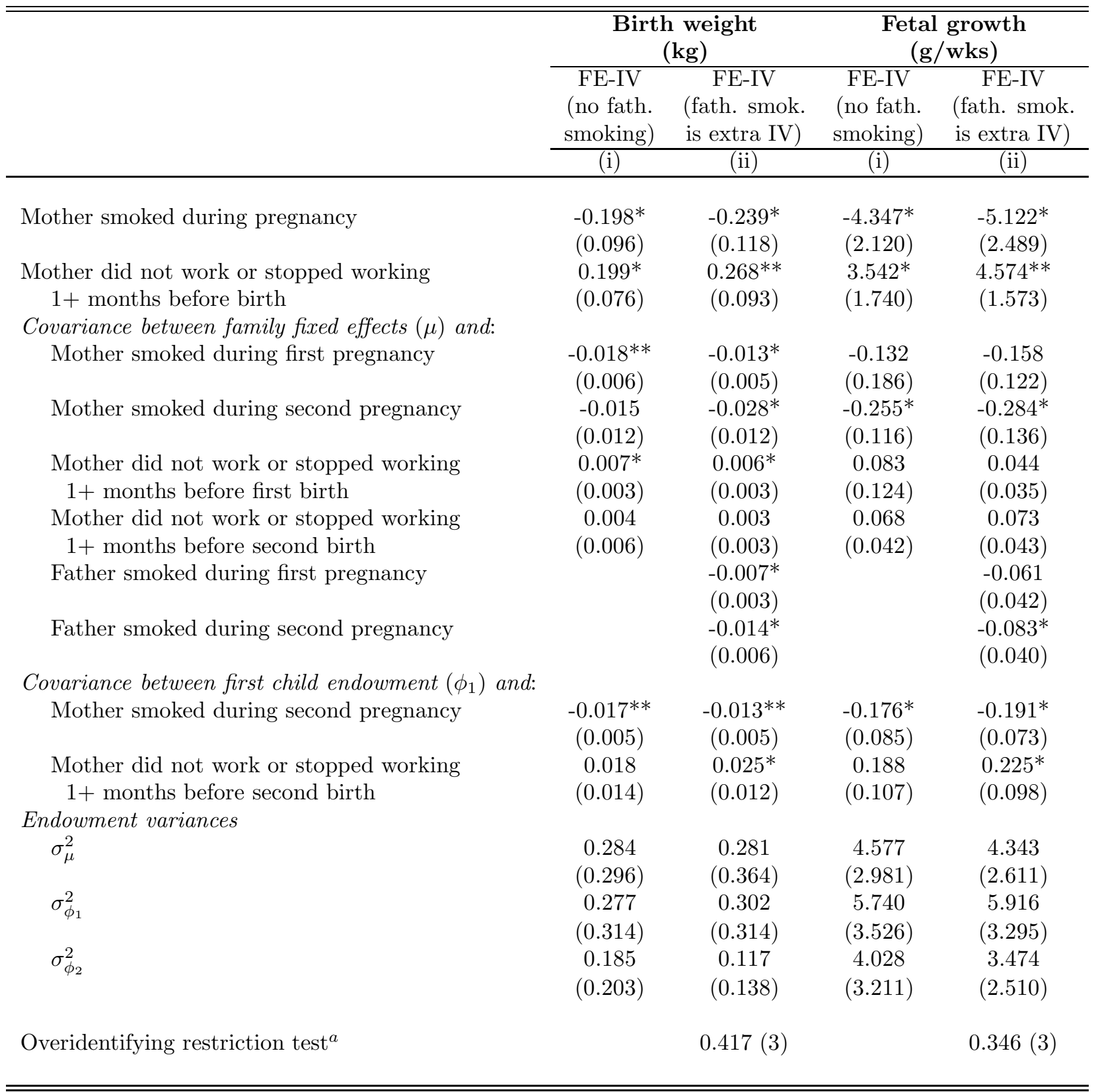

Notes: Estimates are obtained from the FE-IV model estimated using GMM techniques. Standard errors are in parentheses. For definitions and other explanatory variables, see notes to Table 4. Column (i) reports estimates from a specification in which father's smoking is not included, while column (ii) reports a specification in which father's smoking is used as an additional instrument as illustrated in Appendix C. Number of births is 654, and number of mothers is 327.

${ }^{a}$ This row reports the $p$-value (d.f.) of the zero-coefficient restrictions placed on direct and dynamic effects of the additional instrumental variable (father's smoking).

** Statistically significant at the 0.01 level, * statistically significant at the 0.05 level. 
Table 7: OLS Effects of Endowment Shock, Birth Weight, and Earlier Breastfeeding on Breastfeeding Decisions, by Birth Order - NSFG

\begin{tabular}{|c|c|c|c|c|c|c|}
\hline & \multicolumn{3}{|c|}{ Breastfeeding initiation } & \multicolumn{3}{|c|}{ Breastfeeding duration } \\
\hline & $\begin{array}{l}\text { First } \\
\text { child }\end{array}$ & $\begin{array}{c}\text { Second } \\
\text { child }\end{array}$ & $\begin{array}{l}\text { Third } \\
\text { child }\end{array}$ & $\begin{array}{l}\text { First } \\
\text { child } \\
\end{array}$ & $\begin{array}{c}\text { Second } \\
\text { child }\end{array}$ & $\begin{array}{l}\text { Third } \\
\text { child }\end{array}$ \\
\hline Child-specific idiosyncratic endowment $\left(\lambda_{1}\right)$ & $\begin{array}{c}-0.032^{*} \\
(0.014)\end{array}$ & $\begin{array}{c}-0.075^{* *} \\
(0.027)\end{array}$ & $\begin{array}{c}-0.038^{*} \\
(0.016)\end{array}$ & $\begin{array}{c}-1.038^{*} \\
(0.486)\end{array}$ & $\begin{array}{c}-1.183^{*} \\
(0.469)\end{array}$ & $\begin{array}{l}-0.774 \\
(0.941)\end{array}$ \\
\hline First child's birth weight $\left(\beta_{1}\right)$ & & $\begin{array}{c}0.054^{*} \\
(0.024)\end{array}$ & $\begin{array}{c}0.033 \\
(0.024)\end{array}$ & & $\begin{array}{l}0.403^{*} \\
(0.132)\end{array}$ & $\begin{array}{c}0.403 \\
(0.463)\end{array}$ \\
\hline Second child's birth weight $\left(\beta_{2}\right)$ & & & $\begin{array}{c}0.018 \\
(0.026)\end{array}$ & & & $\begin{array}{c}0.088 \\
(0.297)\end{array}$ \\
\hline First child's breastfeeding initiation/duration $\left(\xi_{1}\right)$ & & $\begin{array}{c}0.059^{* *} \\
(0.016)\end{array}$ & $\begin{array}{l}0.051^{*} \\
(0.020)\end{array}$ & & $\begin{array}{c}0.671^{* *} \\
(0.263)\end{array}$ & $\begin{array}{l}0.603^{*} \\
(0.281)\end{array}$ \\
\hline Second child's breastfeeding initiation/duration $\left(\xi_{2}\right)$ & & & $\begin{array}{c}0.032 \\
(0.056)\end{array}$ & & & $\begin{array}{c}0.337 \\
(0.247)\end{array}$ \\
\hline
\end{tabular}

Notes: The dependent variable is a dummy variable for all breastfeeding initiation regressions, and the number of weeks of breastfeeding for children who are breastfeed for all breastfeeding duration regressions. Each column corresponds to a different regression estimated using ordinary least squares. Child-specific idiosyncratic endowment has been obtained from FE-IV regressions as in Table 3, column (i). Other variables included in all regressions are maternal age at birth and its square, and dummy variables for child sex, mother's race and highest educational qualification. Standard errors are in parentheses. Number of births with non-missing information on breastfeeding is 11,864 and number of mothers is 6,014 ; the number of breastfed children is 5,731, and the number of mothers is 3,376 .

** Statistically significant at the 0.01 level, * statistically significant at the 0.05 level. 
Appendix Table A1: OLS Estimates of Maternal Alcohol Consumption, Antenatal Care and Maternal BMI on Birth Outcomes - MCS Sample

\begin{tabular}{lcccccc}
\hline \hline & \multicolumn{3}{c}{ Birthweight (kg) } & \multicolumn{3}{c}{ Fetal growth (g/wks) } \\
\cline { 2 - 7 } & (i) & (ii) & (iii) & (i) & (ii) & (iii) \\
\hline \multirow{2}{*}{ Mother smoked during pregnancy } & $-0.202^{* *}$ & $-0.202^{* *}$ & $-0.196^{* *}$ & $-4.772^{* *}$ & $-4.758^{* *}$ & $-4.597^{* *}$ \\
& $(0.013)$ & $(0.013)$ & $(0.013)$ & $(0.294)$ & $(0.296)$ & $(0.300)$ \\
Mother stopped working & $0.161^{* *}$ & $0.161^{* *}$ & $0.155^{* *}$ & $2.664^{* *}$ & $2.659^{* *}$ & $2.514^{* *}$ \\
1-2 months before birth & $(0.013)$ & $(0.012)$ & $(0.013)$ & $(0.298)$ & $(0.298)$ & $(0.299)$ \\
Mother stopped working & $0.086^{* *}$ & $0.086^{* *}$ & $0.081^{* *}$ & $1.563^{* *}$ & $1.558^{* *}$ & $1.430^{* *}$ \\
3+ months before birth & $(0.021)$ & $(0.021)$ & $(0.020)$ & $(0.460)$ & $(0.460)$ & $(0.460)$ \\
Mother did not work during pregnancy & $0.069^{* *}$ & $0.069^{* *}$ & $0.066^{* *}$ & $1.075^{* *}$ & $1.080^{* *}$ & $1.003^{* *}$ \\
& $(0.016)$ & $(0.016)$ & $(0.016)$ & $(0.352)$ & $(0.352)$ & $(0.352)$ \\
Mother consumed alcohol & $-0.110^{*}$ & $-0.109^{*}$ & -0.097 & $-2.550^{*}$ & $-2.536^{*}$ & -2.235 \\
every day during pregnancy & $(0.053)$ & $(0.053)$ & $(0.052)$ & $(1.182)$ & $(1.184)$ & $(1.152)$ \\
Mother received antenatal care & & 0.005 & 0.004 & & 0.249 & 0.238 \\
in the first trimester & & $(0.013)$ & $(0.013)$ & & $(0.308)$ & $(0.304)$ \\
Body Mass Index (before pregnancy) & & & $0.014^{* *}$ & & & $0.342^{* *}$ \\
& & & $(0.001)$ & & & $(0.027)$ \\
\hline \hline
\end{tabular}

Notes: All estimates are from OLS regressions. Standard errors are in parentheses. For definitions and variables, see notes to Table 2. Number of births (and mothers) is 17,483.

** Statistically significant at the 0.01 level, * statistically significant at the 0.05 level. 
Appendix Table A2: Estimates of Maternal Smoking and Maternal Labor Supply on the Probability of Low Birth Weight, by Sample

$\bar{P}$

Mother smoked during pregnancy

Mother stopped working 1-2 months before birth

Mother stopped working $3+$ months before birth

Mother did not work during pregnancy

Covariance between first child endowment $\left(\phi_{1}\right)$ and: Mother smoked during second pregnancy

Mother stopped working

1-2 months before second birth

Mother stopped working

$3+$ months before second birth

Mother did not work

during second pregnancy

Joint significance of input- $\mu$ covariances

Joint significance of input- $\phi$ covariances

Mother stopped working 1-2 months before birth

Mother stopped working $3+$ months before birth

Mother did not work during pregnancy

Mother smoked during pregnancy

Mother stopped working 1-2 months before birth

Mother stopped working $3+$ months before birth

Mother did not work during pregnancy

Covariance between first child endowment $\left(\phi_{1}\right)$ and:

Mother smoked during second pregnancy

Mother smoked during third pregnancy
Mother smoked during pregnancy

\begin{tabular}{ccc} 
Low Birth Weight \\
(less than & $\mathbf{2 , 5 0 0}$ grams) \\
\hline OLS & FE & FE-IV \\
\hline (i) & (ii) & (iii) \\
\hline
\end{tabular}

BHPS $^{a}$

$\begin{array}{ccc}0.058^{* *} & 0.114 & 0.105^{*} \\ (0.021) & (0.060) & (0.052) \\ -0.052 & -0.064 & -0.066 \\ (0.027) & (0.047) & (0.048) \\ -0.043 & -0.056 & -0.011 \\ (0.029) & (0.049) & (0.038) \\ -0.041 & -0.046 & -0.022 \\ (0.022) & (0.039) & (0.045) \\ & & \\ & & 0.097^{*} \\ & & (0.043) \\ & & -0.015 \\ & & (0.046) \\ & & -0.027^{*} \\ & & (0.012) \\ & & -0.018 \\ & & 0.030) \\ & & 0.018 \\ & & 0.053\end{array}$

$\mathrm{MCS}^{b}$

\begin{tabular}{c}
\hline $0.043^{* *}$ \\
$(0.006)$ \\
$-0.038^{* *}$ \\
$(0.005)$ \\
-0.009 \\
$(0.009)$ \\
-0.011 \\
$(0.006)$
\end{tabular}

\begin{tabular}{ccc}
\multicolumn{3}{c}{$\mathbf{N S F G}^{c}$} \\
\hline $0.031^{* *}$ & 0.036 & $0.047^{*}$ \\
$(0.008)$ & $(0.023)$ & $(0.023)$ \\
-0.009 & -0.014 & -0.041 \\
$(0.009)$ & $(0.014)$ & $(0.043)$ \\
0.004 & -0.020 & -0.006 \\
$(0.012)$ & $(0.018)$ & $(0.019)$ \\
0.003 & -0.012 & -0.022 \\
$(0.006)$ & $(0.011)$ & $(0.023)$ \\
& & \\
& & $0.062^{*}$ \\
& & $(0.028)$ \\
& & 0.016 \\
& & $(0.035)$
\end{tabular}

(continues on next page) 
Appendix Table A2: (continued)

\begin{tabular}{lc}
\hline Mother stopped working & -0.026 \\
$1-2$ months before second birth & $(0.018)$ \\
Mother stopped working & $-0.039^{* *}$ \\
$1-2$ months before third birth & $(0.012)$ \\
Mother stopped working & $-0.051^{*}$ \\
3+ months before second birth & $(0.022)$ \\
Mother stopped working & 0.004 \\
3+ months before third birth & $(0.028)$ \\
Mother did not work & $-0.022^{*}$ \\
during second pregnancy & $(0.010)$ \\
Mother did not work & 0.008 \\
during third pregnancy & $(0.013)$ \\
Covariance between second child endowment $\left(\phi_{2}\right)$ and: & $0.037^{*}$ \\
Mother smoked during third pregnancy & $(0.017)$ \\
& $-0.020^{*}$ \\
Mother stopped working & $(0.009)$ \\
1-2 months before third birth & -0.015 \\
Mother stopped working & $(0.034)$ \\
$3+$ months before third birth & -0.016 \\
Mother did not work & $(0.019)$ \\
during third pregnancy & \\
Joint significance of input- $\mu$ covariances ${ }^{d}$ & 0.003 \\
Joint significance of input- $\phi$ covariances & \\
& 0.020 \\
\hline \hline
\end{tabular}

Notes: The dependent variable is a dummy variable that takes value 1 if the child is low birth weight (defined as less than 2,500 grams), and 0 otherwise. All estimates are marginal effects from linear probability models. Standard errors are in parentheses, with OLS standard errors in the BHPS and NSFG samples being adjusted for clustering at the mother's level. For each of the FE-IV specifications, we report $p$-values of a $\chi^{2}$ test of the joint significance of the input- $\mu$ and input- $\phi$ covariances. For other definitions and variables, see notes to Tables $2-4$.

${ }^{a}$ BHPS: FE-IV estimates are obtained from the two-child family subsample only. Number of births is 1,339 , and number of mothers is 912 .

${ }^{b}$ MCS: Number of births (and mothers) is 17,483 .

${ }^{c}$ NSFG: Number of births is 12,166 , and number of mothers is 6,153 .

${ }^{d}$ Figures are $p$-values of $\chi^{2}$ tests of the joint significance of the input- $\mu$ and input- $\phi$ covariances.

** Statistically significant at the 0.01 level, * statistically significant at the 0.05 level. 
Appendix Table A3: Effects of Maternal and Paternal Smoking on Birth Outcomes, BHPS and MCS Samples

\begin{tabular}{|c|c|c|c|c|c|c|}
\hline & \multicolumn{3}{|c|}{ 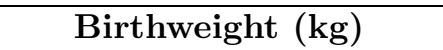 } & \multicolumn{3}{|c|}{ Fetal growth (g/wks) } \\
\hline & OLS & $\mathrm{FE}$ & FE-IV & OLS & $\mathrm{FE}$ & FE-IV \\
\hline & (i) & (ii) & (iii) & (i) & (ii) & (iii) \\
\hline & \multicolumn{6}{|c|}{$\mathbf{B H P S}^{a}$} \\
\hline \multirow[t]{2}{*}{ Mother smoked during pregnancy } & $-0.183^{* *}$ & $-0.204^{*}$ & $-0.208^{*}$ & $-3.971^{* *}$ & $-5.027^{*}$ & $-5.176^{*}$ \\
\hline & $(0.046)$ & $(0.095)$ & $(0.102)$ & $(1.018)$ & $(2.049)$ & $(2.112)$ \\
\hline \multirow[t]{2}{*}{ Father smoked during pregnancy } & -0.026 & -0.004 & -0.008 & -0.634 & 0.329 & -0.054 \\
\hline & $(0.046)$ & $(0.079)$ & $(0.087)$ & $(1.044)$ & $(1.709)$ & $(1.885)$ \\
\hline Joint significance of input- $\mu$ covariances & & & 0.012 & & & 0.009 \\
\hline \multirow[t]{2}{*}{ Joint significance of input- $\phi$ covariances } & & & 0.026 & & & 0.017 \\
\hline & \multicolumn{6}{|c|}{$\mathbf{M C S}^{b}$} \\
\hline \multirow[t]{2}{*}{ Mother smoked during pregnancy } & $-0.194^{* *}$ & & & $-4.536^{* *}$ & & \\
\hline & $(0.013)$ & & & $(0.295)$ & & \\
\hline \multirow[t]{2}{*}{ Father smoked during pregnancy } & $-0.040 * *$ & & & $-0.927^{* *}$ & & \\
\hline & $(0.012)$ & & & $(0.271)$ & & \\
\hline
\end{tabular}

Notes: Standard errors are in parentheses. OLS standard errors in the BHPS sample are adjusted for clustering at the mother's level. For definitions and variables, see notes to Tables 2 and 4.

${ }^{a}$ BHPS: Number of births is 1,339, and number of mothers is 912 in the OLS and FE models, while number of births is 654 and number of mothers is 327 in the FE-IV model (two-child families only).

${ }^{b}$ MCS: Number of births (and mothers and fathers) is 17,483.

${ }^{c}$ Figures are $p$-values of $\chi^{2}$ tests of the joint significance of the input- $\mu$ and input- $\phi$ covariances.

** Statistically significant at the 0.01 level, ${ }^{*}$ statistically significant at the 0.05 level. 